\title{
OPEN Dynamic patterns of YAP1 expression and cellular localization in the developing and injured utricle
}

\begin{abstract}
Vikrant Borse $^{1 \bowtie}$, Matthew Barton ${ }^{1,3}$, Harry Arndt $^{1}{ }^{1}$ Tejbeer Kaur $^{2}$ \& Mark E. Warchol ${ }^{1 \bowtie}$
The Hippo signaling pathway is a key regulator of tissue development and regeneration. Activation of the Hippo pathway leads to nuclear translocation of the YAP1 transcriptional coactivator, resulting in changes in gene expression and cell cycle entry. Recent studies have demonstrated the nuclear translocation of YAP1 during the development of the sensory organs of the inner ear, but the possible role of YAP1 in sensory regeneration of the inner ear is unclear. The present study characterized the cellular localization of YAP1 in the utricles of mice and chicks, both under normal conditions and after HC injury. During neonatal development, YAP1 expression was observed in the cytoplasm of supporting cells, and was transiently expressed in the cytoplasm of some differentiating hair cells. We also observed temporary nuclear translocation of YAP1 in supporting cells of the mouse utricle after short periods in organotypic culture. However, little or no nuclear translocation of YAP1 was observed in the utricles of neonatal or mature mice after ototoxic injury. In contrast, substantialYAP1 nuclear translocation was observed in the chicken utricle after streptomycin treatment in vitro and in vivo. Together, these data suggest that differences in YAP1 signaling may partially account for the differing regenerative abilities of the avian vs. mammalian inner ear.
\end{abstract}

The hair cells of the inner ear convert mechanical stimuli into electrical signals that mediate the senses of hearing and balance. Ongoing interactions between hair cells, their neighboring supporting cells and afferent and efferent neurons are essential for proper sensory function ${ }^{1}$. In mammals, loss of hair cells leads to permanent deficits in hearing and equilibrium ${ }^{2,3}$. In contrast, the ears of non-mammals can regenerate new hair cells after acoustic trauma or ototoxic injury ${ }^{4-7}$. The vestibular organs of mammals possess a limited capability to produce new hair cells ${ }^{8}$, but the extent of regeneration may not be sufficient for complete recovery of sensory function.

At the cellular level, two distinct mechanisms have been shown to produce new hair cells after damage ${ }^{9}$. In some sensory organs, supporting cells can re-enter the cell cycle in response to hair cell injury, resulting in the production of new hair cells and supporting cells ${ }^{5-7}$. In other cases, supporting cells can undergo direct transdifferentiation, converting into new hair cells without proliferating ${ }^{10-12}$. Multiple signaling pathways, such as Notch, Wnt, FGF and VEGF, have been shown to be involved in hair cell regeneration and functional recovery after damage ${ }^{13,14}$. Hair cell-specific transcription factors and other transcriptional regulators such as p2 $7^{\text {Kip } 1}$, GATA3, ATOH1, and POU4F3 are also involved in the regenerative process ${ }^{15-18}$. Present knowledge of the pathways responsible for regeneration are incomplete, but identification of these signals may facilitate the development of methods for restoration of function in the inner ears of humans.

The Hippo/YAP1 pathway is an evolutionarily conserved signaling network known to be involved in regulating tissue size and cell number during development ${ }^{19-24}$. The transcriptional coactivator YAP1 is the primary effector of Hippo signaling. Under normal conditions, YAP1 is sequestered in the cytoplasm and targeted for degradation. However, activation of upstream Hippo pathway molecules or mechanical stimulation of cells can result in the nuclear translocation of YAP1, leading to changes in gene expression that promote cell division ${ }^{25}$. YAP1 signaling has been shown to play an important role in the development of the mouse cochlea and utricle ${ }^{26}$, 27. A prior study has reported that reduced mechanical stress in the sensory epithelium of the growing utricle promotes nuclear translocation of YAP1 and increased proliferation ${ }^{26}$. It is not clear, however, whether YAP1 signaling also regulates regeneration in the mature ear.

${ }^{1}$ Department of Otolaryngology, School of Medicine, Washington University in Saint Louis, 660 South Euclid Ave, Box 8115, St Louis, MO 63110, USA. ${ }^{2}$ Department of Biomedical Sciences, Creighton University School of Medicine, Nebraska, USA. ${ }^{3}$ Matthew Barton is deceased. ${ }^{\circledR}$ email: borsevikrant@wustl.edu; mwarchol@wustl.edu 
The present study profiled the expression pattern of YAP1 in the neonatal and mature mouse utricle and investigated the role of YAP1 signaling after selective hair cell lesion. We found that, during neonatal development, YAP1 is present in supporting cells, and is transiently expressed in some hair cells. We also observed transient nuclear translocation of YAP1 in supporting cells of mouse utricles shortly after placement in organotypic culture. However, selective hair cell ablation in Pou4f3-huDTR mice did not induce significant YAP1 nuclear translocation. In contrast, hair cell injury caused nuclear translocation of YAP1 in the chicken utricle. The results suggest that YAP1 can respond to mechanical forces acting on the sensory epithelium, but that hair cell injury in the mammalian utricle is not sufficient to promote YAP1 entry into the nucleus. Our data also reveal differences in the injury response of the inner ear in birds vs. mammals.

\section{Results}

Developmental profile of YAP1 expression in the mouse utricle in vivo. Initial studies characterized the expression patterns of YAP1 in the mouse utricle during the first 15 days of postnatal development. Previous data indicate that growth and differentiation in the mouse utricle initially occurs in the striolar and medial regions, with the lateral region being the last to differentiate ${ }^{28-30}$. We obtained images from the lateral extrastriolar (L), striolar (S) and medial extrastriolar (M) regions of whole mount utricles at postnatal days P0, P7 and P15. Specimens were immunolabeled for myosin Vlla (hair cells), Sox2 (supporting cells and type II hair cells) and YAP1. Consistent with earlier studies ${ }^{26}$, we found that YAP1 expression was mainly confined to the cytoplasm of supporting cells. In early stage post-natal utricles, we also observed cytoplasmic YAP1 expression in a subset of hair cells, but such expression was lost by P15 (Fig. 1A-C). Nearly all YAP1-expressing hair cells were also immunoreactive for Sox2 and were most numerous in the lateral region of the sensory epithelium. Quantitative analysis verified that the numbers of YAP $1^{+} / \mathrm{Sox}^{+}$hair cells diminished during postnatal development (Fig. 1D). In agreement with earlier finding ${ }^{28-30}$, we also observed a significant increase in Sox $2^{-}$hair cells $(\mathrm{p}<0.0001)$ and an increase in hair cell density between P0 and P15 (Lateral region: $\mathrm{p}=0.0265$, Striolar region: $\mathrm{p}=0.0094$, and Medial region: $\mathrm{p}=0.0265)($ Fig. $1 \mathrm{D}, \mathrm{E})$.

We also characterized the growth of the maturing utricle, by quantifying the surface area of the utricular sensory epithelium at P0, P7 and P15. At P0, the surface area was $0.163 \pm 0.02 \mathrm{~mm}^{2}$, while at P7 it was $0.175 \pm 0.007 \mathrm{~mm}^{2}$, and at $\mathrm{P} 15$ it was $0.189 \pm 0.009 \mathrm{~mm}^{2}(\mathrm{n}=3-6)$. These values are in general agreement with data reported by Burns et al. ${ }^{29}$. Utricles fixed at $\mathrm{P} 0$ and $\mathrm{P} 3$ also displayed evidence of cell division. Mitotic figures at the metaphasic and anaphasic stages were occasionally observed in Sox2-expressing cells in the lateral region of the utricle. Nuclei of these cells showed light granular YAP1 immunolabeling (Fig. 2A). Utricles fixed between P0 and P7 also contained a small number of 'atypical' hair cells, which possessed large globular cytoplasm and slightly elongated nuclei. Such cells were observed in medial and striolar regions of the sensory epithelium (density: 1-2 per 10,000 $\mu^{2}$ ) and displayed cytoplasmic immunoreactivity for YAP1 and nuclear immunoreactivity for Sox2 (Fig. 2B). We further found that the size of hair cell nuclei underwent a significant $(\mathrm{p}<0.0001$, $\mathrm{P} 0$ vs P15) decrease during postnatal development (Fig. 2C,D). At P0, the average hair cell nuclear area in the striolar region was $72.40 \pm 14.24 \mu^{2}$. At P7 and P15, average hair cell nuclear area in the striola was decreased to $44.23 \pm 3.35 \mu \mathrm{m}^{2}$, and $43.50 \pm 4.50 \mu \mathrm{m}^{2}$, respectively $(\mathrm{n}=3-6)$. A similar pattern was observed in the extrastriolar regions (Fig. 2D). Regression correlation analysis between hair cell density and nuclear area indicated a strong negative (Pearson's) correlation, with $r$ value of -0.8377 and $p$ value $<0.0001$ (Fig. 2E).

Placement in organotypic culture evokes transient nuclear translocation of YAP1. Nuclear translocation of YAP1 is regulated by multiple mechanical stimuli, such as matrix stiffness, epithelial stretching and cell density ${ }^{19-26}$. To test the effects of the mechanical environment on YAP1 localization, we removed utricles from P15 mice and placed them in organotypic culture. Explanted utricles were placed in Matrigel-coated Mat-Tek dishes that contained $100 \mu \mathrm{l}$ of culture medium. The surface of the sensory epithelium was placed in contact with the Matrigel substrate (i.e., lumenal side down) and a small amount of pressure was applied to ensure attachment. Cultured utricles were fixed after 2-24 h in vitro and were then labeled with Sox2 and YAP1 antibodies. Examination of these specimens revealed transient nuclear translocation of YAP1 in supporting cells between $2-6 \mathrm{~h}$ in vitro (Fig. 3A). After $2 \mathrm{~h}$ in culture, nuclear YAP1 was observed in $68.2 \pm 15.4 \%$ and $70.3 \pm 20.4 \%$ of supporting cells in the extrastriolar and striolar regions, respectively $(n=3-6)$. After $6 \mathrm{~h}$, the degree of YAP1 nuclear translocation was observed in $75.1 \pm 15.6 \%$ of extrastriolar and $79.5 \pm 12.4 \%$ of striolar supporting cells. In contrast, utricles that had been in culture for $24 \mathrm{~h}$ contained $9.3 \pm 9.7 \%$ and $17.8 \pm 14.7 \%$ YAP1-labeled nuclei in extrastriolar and striolar regions, respectively. These observations suggest that removal from the in vivo environment and placement in culture leads to temporary YAP1 nuclear translocation, but the patterns of YAP1 localization returned to normal by $24 \mathrm{~h}$ in vitro (Fig. 3C).

The transient YAP1 nuclear translocation that was observed in cultured utricles may have been caused by attachment to the Matrigel coated dish. To test this, we cultured mouse utricles as free-floating samples in both Matrigel-coated and uncoated MatTek dishes. Utricles were maintained in vitro for $2 \mathrm{~h}$ and $6 \mathrm{~h}$, since we previously observed maximum translocation at those times (Fig. 3). Following fixation and immunoprocessing, we observed a similar degree of YAP1 nuclear translocation in specimens cultured in both Matrigel-coated and uncoated dishes (Fig. 3B,D).

The patterns of YAP1 immunolocalization in cultures of the mouse utricle were also unaffected by ototoxic injury. Utricles were explanted from mice at $\sim 1$ month postnatal and placed in culture in uncoated MatTek dishes. Some utricles $(n=5)$ were treated with $3 \mathrm{mM}$ neomycin, while control specimens $(n=5)$ were cultured identically, but without neomycin. After $24 \mathrm{~h}$ in vitro, specimens were fixed and processed for labeling of hair cells and YAP1. Immunolabeling of myosin VIIa (Fig. 3E) indicated that neomycin treatment led to a reduction in hair density $\left(17.6 \pm 8.8\right.$ hair cells $/ 2500 \mu \mathrm{m}^{2}$ in neomycin treated utricles vs. $42.8 \pm 4.8$ hair cells $/ 2500 \mu \mathrm{m}^{2}$ in 
A

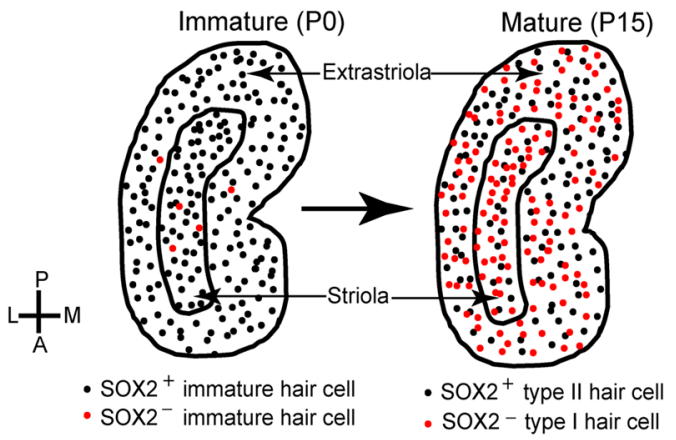

$\mathrm{B}$

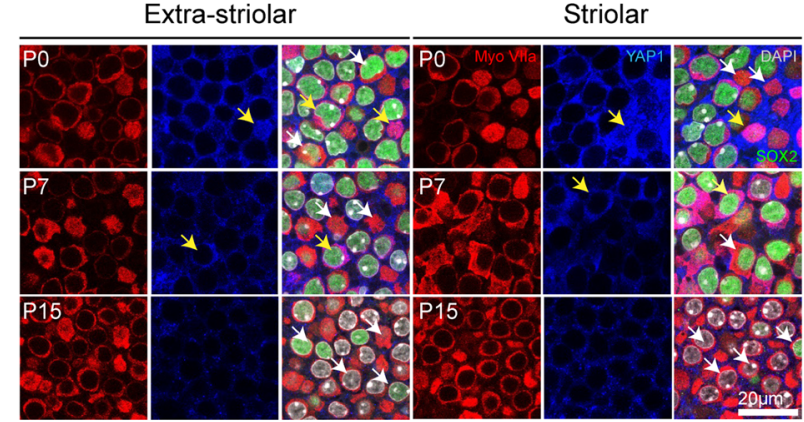

D

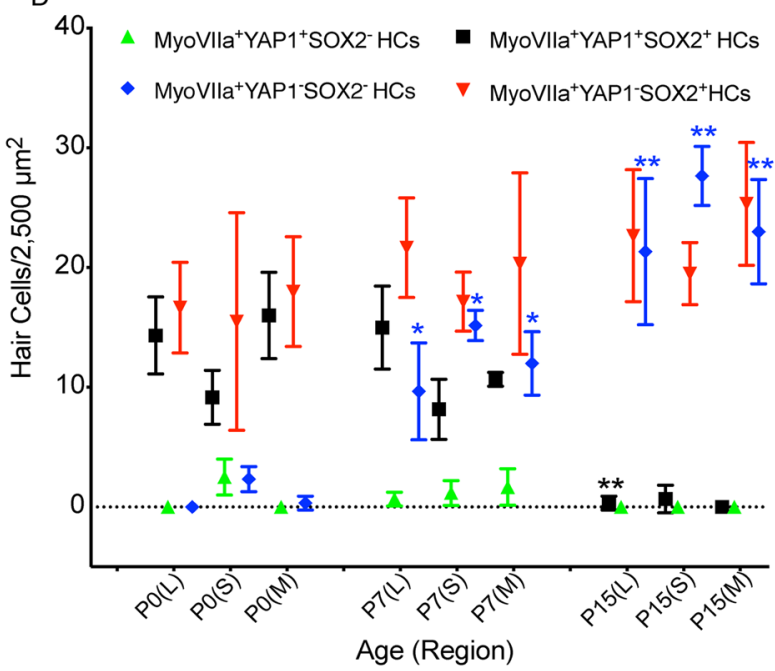

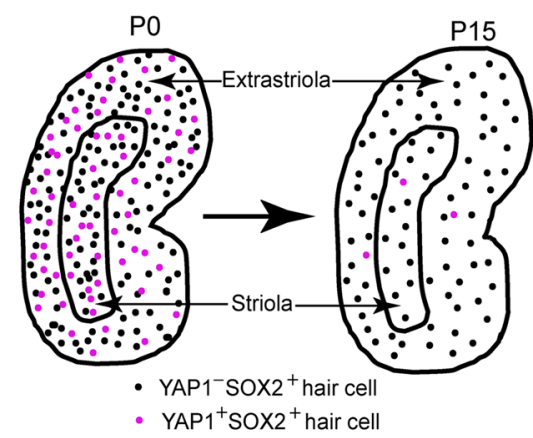

C

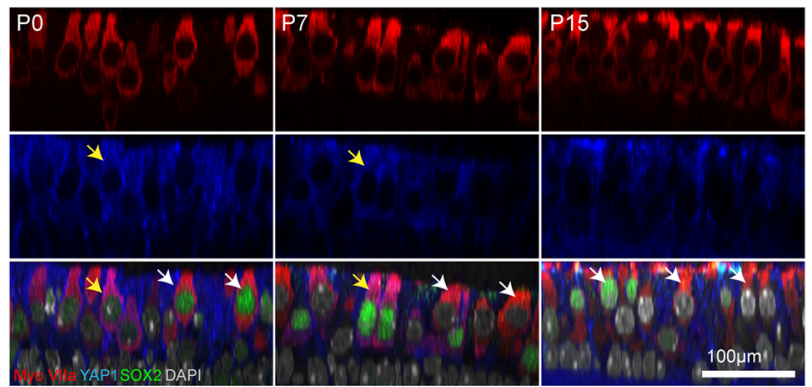

E

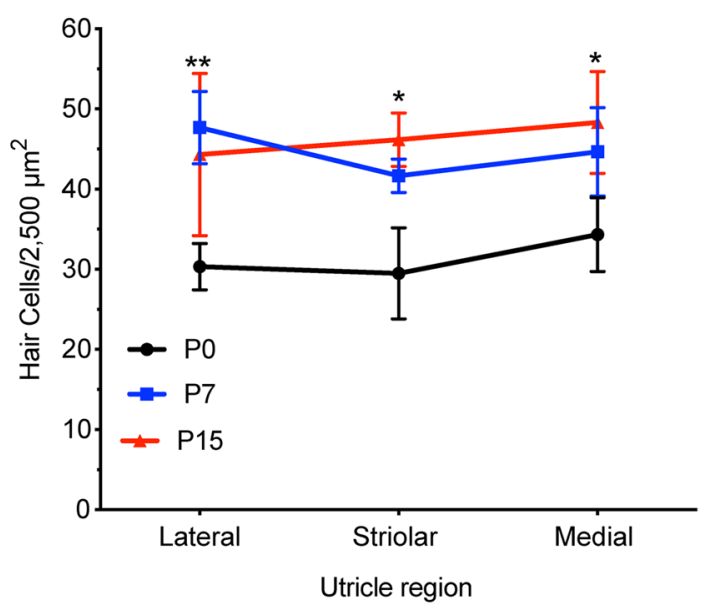

Figure 1. YAP1 expression profile in the developing mouse utricle. Mouse utricles were collected at postnatal days 0 (P0), P7 and P15. Immunostaining was performed using antibodies against Myosin VIIa (hair cell marker, red), SOX2 (green), and YAP1 (blue). All cell nuclei were labeled with DAPI (grey). One or two images were taken from lateral (L) and medial (M) extrastriolar regions and from the striolar (S) region of each utricle. (A) Schematic representation of molecular and cellular changes in hair cells during utricular development. (B) YAP1-positive hair cells (magenta) were observed at P0 and P7, but were very rare at P15. Yellow arrows indicate MyoVlla ${ }^{+} \mathrm{YAP}^{+}$hair cells (magenta) and white arrows indicate MyoVlla ${ }^{+} \mathrm{YAP} 1^{-}$hair cells (red). Representative images were taken from XY planes of Z-stack images. (C) Representative orthogonal images showing YZ planes of P0, P7 and P15 mouse utricles. Yellow arrows indicate MyoVlla ${ }^{+} \mathrm{YAP}^{+} \mathrm{SOX}^{+/-}$hair cells (magenta) and white arrows indicate MyoVlla ${ }^{+} \mathrm{YAP}^{-} \mathrm{SOX}^{+/-}$hair cells (red). (D,E) Quantitative data on utricle hair cell density, YAP1 and SOX2 expression during postnatal development. All data were obtained from 50 X $50 \mu \mathrm{m}$ regions within the lateral extrastriolar, striolar and medial extrastriolar regions of each utricle. (C) During postnatal development, we observed significant increases in MyoVlla ${ }^{+} Y A P 1^{-S O X} 2^{-}$hair cells (blue) $(\mathrm{p}<0.0001)$ and decreases in MyoVlla ${ }^{+} \mathrm{YAP}^{+} \mathrm{SOX} 2^{+}$hair cells (black) $(\mathrm{L} \mathrm{p}=0.0013)$ relative to P0. MyoVlla ${ }^{+} \mathrm{YAP}^{-} \mathrm{SOX} 2^{+}$ hair cells (red) and MyoVlla ${ }^{+}$YAP1 ${ }^{+}$SOX2- hair cells (green) did not change (relative to P0). (D) Increases in hair cell density were observed throughout the utricle at P15, relative to P0. Data expressed as mean \pm SD. Statistical test was two-way ANOVA followed by Tukey's post hoc test $\left({ }^{\star} \mathrm{p}\right.$ indicate significance relative to P0 and ${ }^{\star *} \mathrm{p}$ indicate significance relative $\mathrm{P} 0$ as well as $\mathrm{P} 7, \mathrm{p}$ value $<0.05)$. $\mathrm{N}=3-6$ utricles. 
A

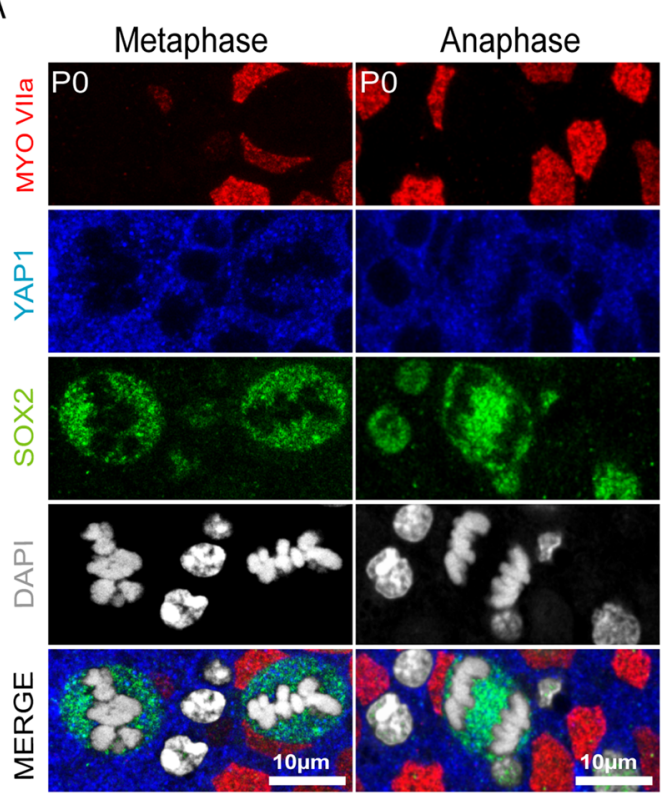

B

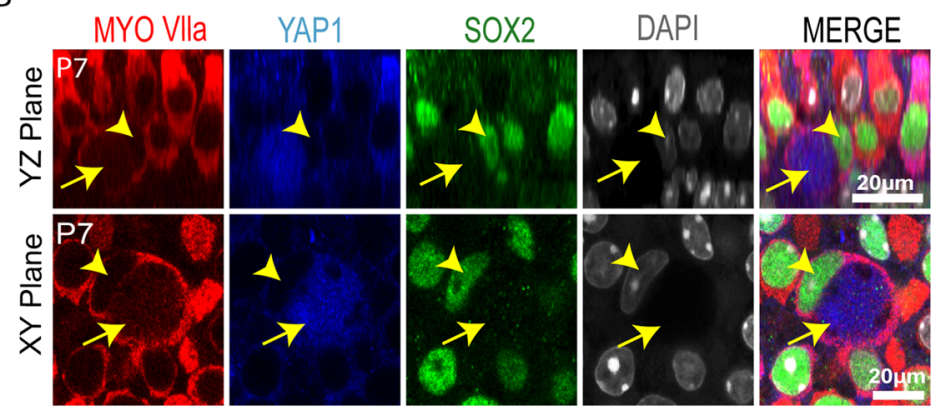

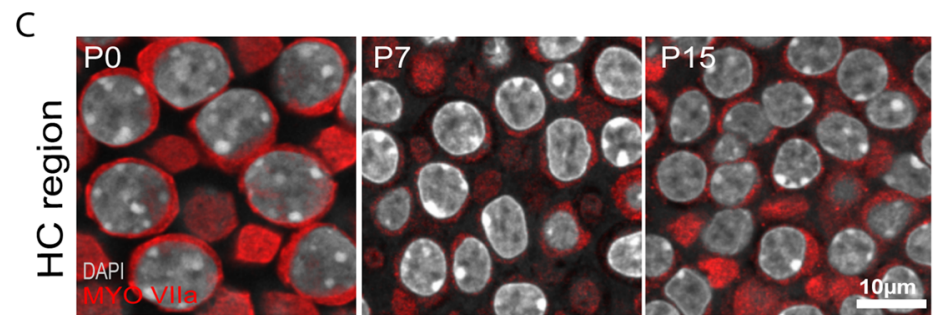

D

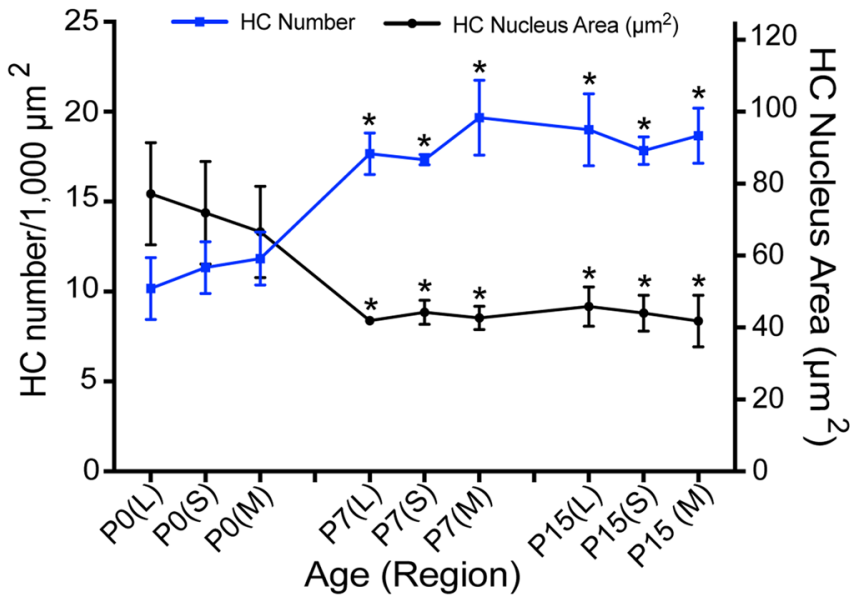

$\mathrm{E}$

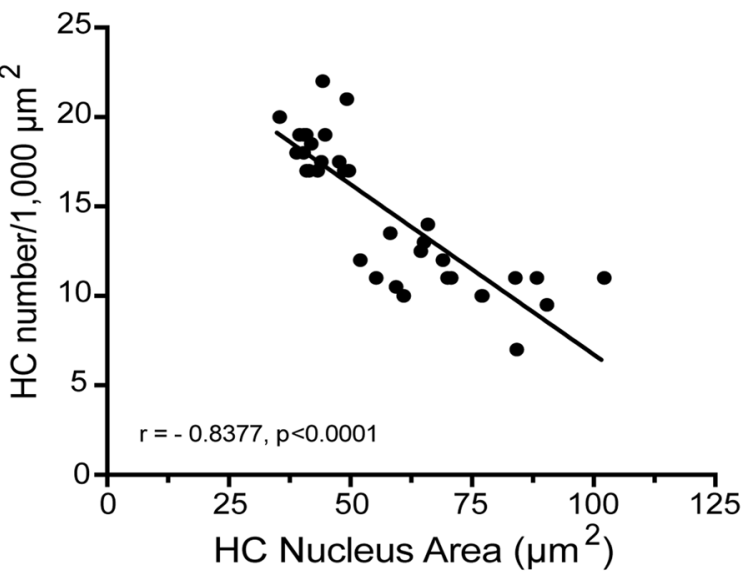

Figure 2. Mitotic cells, atypical hair cells and the decrease in hair cell nuclear area in the developing mouse utricle. (A) Confocal images of mitotically dividing cells showing metaphasic and anaphasic chromosome alignment in whole mount utricles at P0, with immunolabels for Myosin VIIa (red), YAP1 (blue), SOX2 (green) and DAPI (grey). Light granular labeling of YAP1 was observed in mitotically dividing SOX2-positive cells. (B) High levels of YAP1immunolabeling (blue) were observed in a small population of Myosin VIIa (red) and SOX2 (green) double-positive 'atypical hair cells (yellow arrow; yellow arrowhead points at the SOX2 positive nucleus). Images were obtained at P7. (C) Confocal images from the developing mouse utricle, showing changes in the size of hair cell nuclei. Labels: Myosin VIIa (red), and DAPI (grey). (D,E) Quantitative data on utricle hair cell density and hair cell nuclear area during postnatal development. All data were obtained from $1000 \mu \mathrm{m}^{2}$ regions within the lateral extrastriolar, striolar and medial extrastriolar regions. (D) At P7 and P15, a significant increase in hair cell number and decrease in hair cell nucleus area was observed throughout the utricle, relative to P0 $(\mathrm{p}<0.0001)$. (E) Significant negative Pearson correlation was observed between hair cell number and nuclear area in the developing mouse utricle $(\mathrm{p}<0.0001)$. Data expressed as mean \pm SD. Statistical test used two-way ANOVA followed by Bonferroni's post hoc test ( ${ }^{*} \mathrm{p}$ value $<0.05$ relative to $\left.\mathrm{P} 0\right)$. $\mathrm{N}=3-6$ utricles.

controls, $\mathrm{p}=4.5 \times 10^{-7}$ ). However, very similar patterns of YAP1 localization were observed in both neomycintreated and control utricles. Occasional YAP1-labeled nuclei were observed (data not shown), but they were rare and did not differ between lesioned utricles and untreated controls.

Selective hair cell ablation in Pou4f3-huDTR mice does not cause nuclear translocation of YAP1. The above data on changes in YAP1 localization were obtained from organotypic cultures of the 
mouse utricle. Additional experiments examined YAP1 localization after injury in vivo. These studies employed Pou4f3-huDTR transgenic mice, in which one allele of Pou4f3 is replaced by a gene encoding the human form of $H B E G F$ (the 'diphtheria toxin receptor'), thus permitting the selective ablation of hair cells via systemic treatment with diphtheria toxin ${ }^{31,32}$. Treatment of mature Pou4f3-huDTR mice with a single $25 \mathrm{ng} / \mathrm{gm}$ injection of diphtheria toxin (DT) leads to partial loss of vestibular hair cells ${ }^{12,31,32}$. In our experiments, Pou4f3-huDTR and Pou $4 \mathrm{f} 3+/+$ (WT control) mice (4-6 weeks of age) received a single $25 \mathrm{ng} / \mathrm{ml}$ injection of DT, and utricles were examined after 7- and 14-days recovery. Fixed specimens were immunolabeled for myosin Vlla, Sox2 and YAP1, and imaged using confocal microscopy. Resulting data showed loss of myosin VIIa-labeled hair cells in the striolar and extrastriolar regions of Pou4f3-huDTR mice, relative to WT controls. However, this lesion did not lead to increased YAP1 nuclear translocation in the striolar or extrastriolar regions of either the Pou4f3-huDTR or WT utricles at either time point (Fig. 4A,B).

We next examined whether a severe lesion to the sensory epithelium was capable of causing nuclear translocation of YAP1. Unexpectedly, we found that a single $5 \mathrm{ng} / \mathrm{gm}$ injection of DT given to Pou4f3-huDTR mice at $\mathrm{P} 5$ resulted in a massive lesion in the sensory epithelium, that involved the loss of both hair cells and supporting cells (Fig. 5A). This cell loss created a large epithelial 'wound', that lacked any cells and likely caused disruption of the fluid barrier between endolymph and perilymph. Such epithelial wounds were evident between 5-7 days after DT treatment, but had closed by 14 days post-DT (Fig. 5B). To characterize the recovery process, we quantified cell density and epithelial repair as a function of recovery time (Fig. 5C,D). The wound perimeters were comprised of cables of filamentous actin, that were clearly labeled by phalloidin (Fig. 5E',E”, arrows). Phalloidin labeling suggested that cells in the repaired epithelium had undergone mechanical stretching, a pattern that was consistent with epithelial closure via concentric migration of the remaining cells (Fig. 5E'”, E'”). However, despite both the extensive lesion and the subsequent epithelial repair process, we did not observe nuclear translocation of YAP1 in epithelial cells at either 7- or 14-days post-DT (Fig. 5E"',E'”').

Ototoxic damage to the chick utricle promotes nuclear translocation of YAP1. A final series of studies characterized changes in YAP1 localization in the chicken utricle after ototoxic injury. Unlike the mammalian inner ear, the auditory and vestibular organs of birds are able to quickly regenerate hair cells after acoustic trauma or ototoxicity. The molecular mechanisms that are permissive for regeneration are not known, but we hypothesized that nuclear translocation of YAP1 may be an early signal that initiates regeneration in the avian ear. We first examined YAP1 immunoreactivity in the normal (undamaged) utricle of chickens at 2-3 weeks post-hatch. Those specimens contained ubiquitous labeling for YAP1 in the cytoplasm of supporting cells, but no YAP1 labeling in hair cells (Fig. 6A). We also observed rare immunolabeling for YAP1 in supporting cell nuclei $(\sim 1$ cell/utricle; Fig. 6 A, arrow). We next profiled changes in YAP1 localization after aminoglycoside ototoxicity in vivo. Chicks received three injections of $1200 \mathrm{mg} / \mathrm{kg}$ streptomycin (one/day for three days; $\mathrm{n}=5$ injected chicks and 6 uninjected brood-mate controls). At $24 \mathrm{~h}$ after the final injection, animals were euthanized and utricles were fixed and processed for immunohistochemical labeling. Labeling for myosin VIIa and phalloidin revealed a partial hair cell lesion in the striolar region, but very limited (or no) hair cell loss in the extrastriolar region (Fig. 6B). We quantified the numbers of cells with nuclear YAP1 immunoreactivity from three $50 \times 50 \mu \mathrm{m}$ striolar regions, located near the anterior, middle and posterior portions of the utricles ( $n=9$ utricles from streptomycin-treated chicks and 10 utricles from uninjected controls). The loss of hair cells in the striolar region was accompanied by increased numbers of supporting cells with YAP1-labeled nuclei (Fig. 6B, arrows). In contrast, nuclear immunoreactivity for YAP1 in the extracellular region (which did not show evidence of hair cell loss) was very rare (Fig. 6C,D). We next used organotypic culture methods to examine changes in YAP1 localization after severe hair cell lesion. Chick utricles were explanted and placed in organotypic culture, following previously described methods $\mathrm{s}^{33}$. Utricles $(\mathrm{n}=8)$ were incubated for $24 \mathrm{~h}$ in medium that contained $1 \mathrm{mM}$ streptomycin, which results in the death $>90 \%$ of the hair cell population ${ }^{33}$. Control utricles $(n=8)$ were maintained in parallel, but did not receive streptomycin. All cultures were rinsed after $24 \mathrm{~h}$, fed fresh (streptomycin-free) medium and allowed to recover for $48 \mathrm{~h}$. At this point, utricles were fixed and immunolabeled for myosin VIIa and YAP1, filamentous actin was labeled with phalloidin and cell nuclei were labeled with DAPI. Cultured utricles that did not receive streptomycin (controls) possessed largely intact hair cells as well as a few YAP1-labeled supporting cells (Fig. 7A, top row). However, streptomycin-treated utricles displayed evidence of severe hair cell lesions throughout the utricle, and this was accompanied by nuclear immunoreactivity for YAP1 in numerous supporting cells (Fig. 7A, bottom row). Together, these data indicate that the loss of hair cells from the chick utricle leads to nuclear translocation of YAP1 protein. To determine whether YAP1 signaling was essential for the onset of regeneration, we next treated lesioned utricles with verteporfin, which blocks the association between YAP1 and TEAD cofactors and prevents DNA binding of the YAP1 complex. Utricles were placed in culture and treated $24 \mathrm{~h}$ in $1 \mathrm{mM}$ streptomycin. They were then rinsed and maintained for an additional $48 \mathrm{~h}$ in medium that contained $1.0 \mu \mathrm{M}$ verteporfin or $0.1 \%$ DMSO (controls, $\mathrm{n}=6$ utricles/condition). Proliferating cells were labeled by addition of the BrdU to the culture medium for the final $24 \mathrm{~h}$ in vitro (Fig. 7B). Following immunoprocessing, BrdU-labeled nuclei were quantified from three $100 \times 100 \mu \mathrm{m}$ regions that were distributed throughout the extrastriolar region of each utricle. Utricles treated in DMSO (controls) contained 55.1 \pm 20.7 BrdU-labeled cells $/ 10,000 \mu \mathrm{m}^{2}$, while treatment with $1.0 \mu \mathrm{M}$ verteporfin reduced the level of supporting cell proliferation to $13.0 \pm 6.1 \mathrm{BrdU}$ labeled cells $/ 10,000 \mu \mathrm{m}^{2}(\mathrm{p}=0.0008)$.

\section{Discussion}

The objective of this study was to characterize the cellular localization of YAP1 in the utricles of mice and chicks, both in the normal ear and in response to hair cell injury. YAP1 is a transcriptional coactivator that normally resides in the cytoplasm. Under certain conditions, however, YAP1 can translocate to the nucleus, where it 
A

A Attached Culture
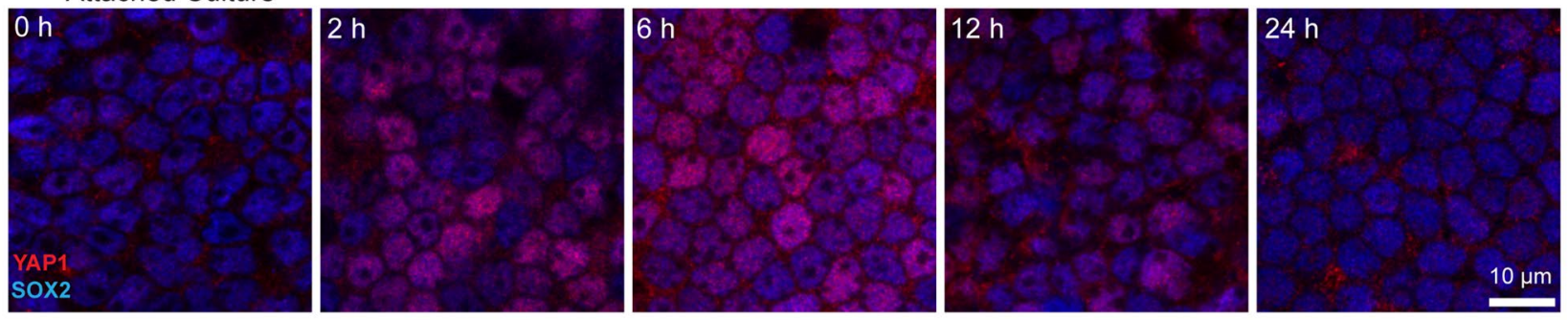

B

Floating Culture
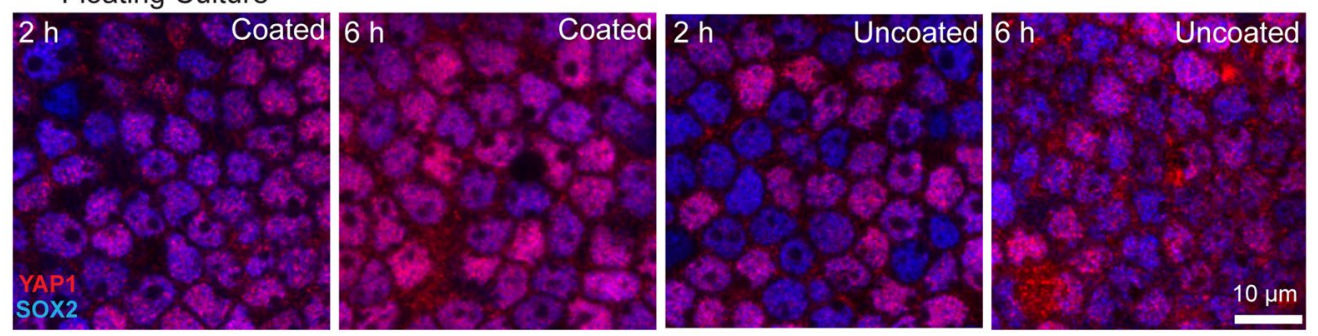

C
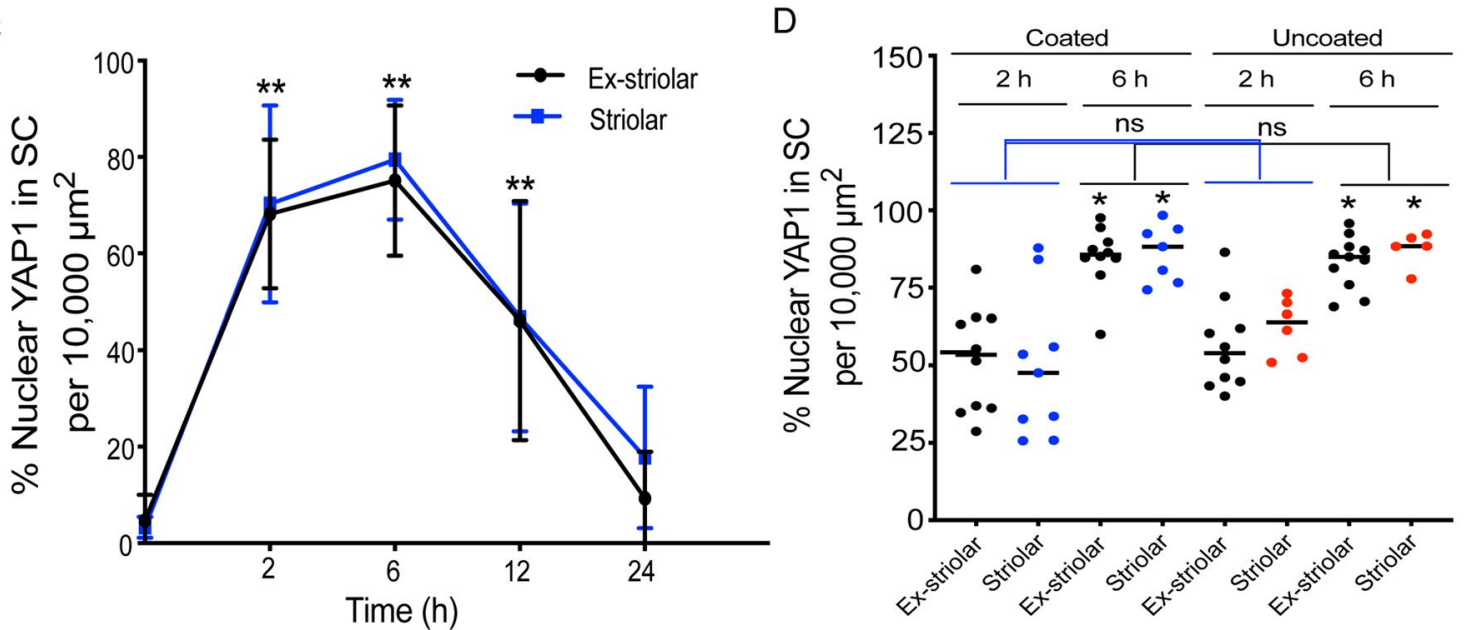

E
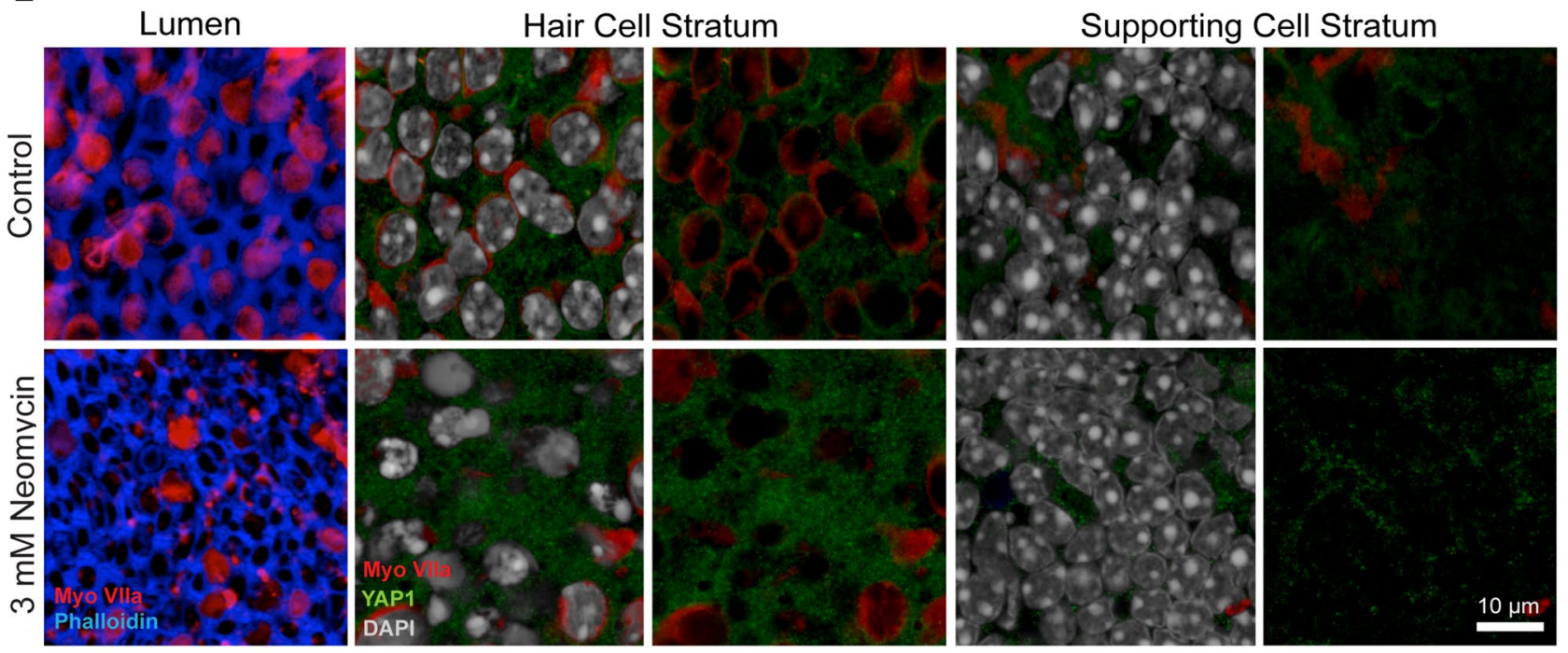
4Figure 3. Transient nuclear translocation of YAP1 in organotypic culture of the mouse utricle. (A) Utricles were explanted from CD1 mice at P15, and attached to Matrigel-coated dishes. Specimens were fixed and examined after 0-24 h in culture. Confocal images show supporting cells of cultured utricles immunolabeled for YAP1 (red) and SOX2 (blue). (B) Utricles were explanted at P15 and cultured in a Matrigel-coated or uncoated dishes as free-floating samples. Cultures were fixed and examined after 2 and $6 \mathrm{~h}$ in vitro. Confocal images show supporting cells of cultured utricles immunolabeled for YAP1 (red) and SOX2 (blue). (C) Quantitative data on the percentage of supporting cells with nuclear YAP1 immunoreactivity. All data were obtained from $10,000 \mu \mathrm{m}^{2}$ regions within the extrastriolar and striolar regions of each utricle. There was a significant increase in nuclear YAP1 immunolabeling at $2 \mathrm{~h}, 6 \mathrm{~h}$ and $12 \mathrm{~h}$ in vitro, relative to specimens fixed immediately after explantation $(0 \mathrm{~h})(\mathrm{p}<0.0001,12 \mathrm{~h}$, Ex-striolar $\mathrm{p}=0.0027$, Striolar $\mathrm{p}=0.0198)$. (D) Quantitative data on the percentage of supporting cells with YAP1-labeled nuclei. All data were obtained from $10,000 \mu \mathrm{m}^{2}$ regions within the extrastriolar and striolar regions of each utricle. There was no significant increase in the percentage of cells with nuclear YAP1 at $2 \mathrm{hr}$ and $6 \mathrm{hr}$ time points between the coated and uncoated cultures. However, there was a significant increase in nuclear YAP1 immunolabeling in utricles cultured in coated and uncoated dishes at the $6 \mathrm{hr}$ time point, vs. those cultured for $2 \mathrm{hr}(\mathrm{p}<0.0001)$. (E) Effects of culture in neomycin on YAP1 nuclear immunoreactivity in supporting cells. Images at far left show the lumen of the sensory epithelium in control and neomycin-treated utricles. Culture for $24 \mathrm{~h}$ in $3 \mathrm{mM}$ neomycin led to reduced numbers of hair cells (red). Remaining images show z-sections through the sensory epithelia of control and neomycin-treated utricles, at the level of hair cell nuclei (middle images) and supporting cell nuclei (images at right). Each z-section is shown with and without DAPI-labeled nuclei (grey). Regardless of treatment condition, immunoreactivity for YAP1 (green) was primarily confined to the cytoplasm of supporting cells. Data expressed as mean \pm SD. Statistical test was one-way ANOVA followed by Bonferroni’s post hoc test $\left({ }^{\star} \mathrm{p}\right.$ value $\left.<0.05\right)\left({ }^{\star *}\right.$ p-value $<0.05$ for Ex-striolar and Striolar both region). $\mathrm{N}=3-6$ utricles.

A

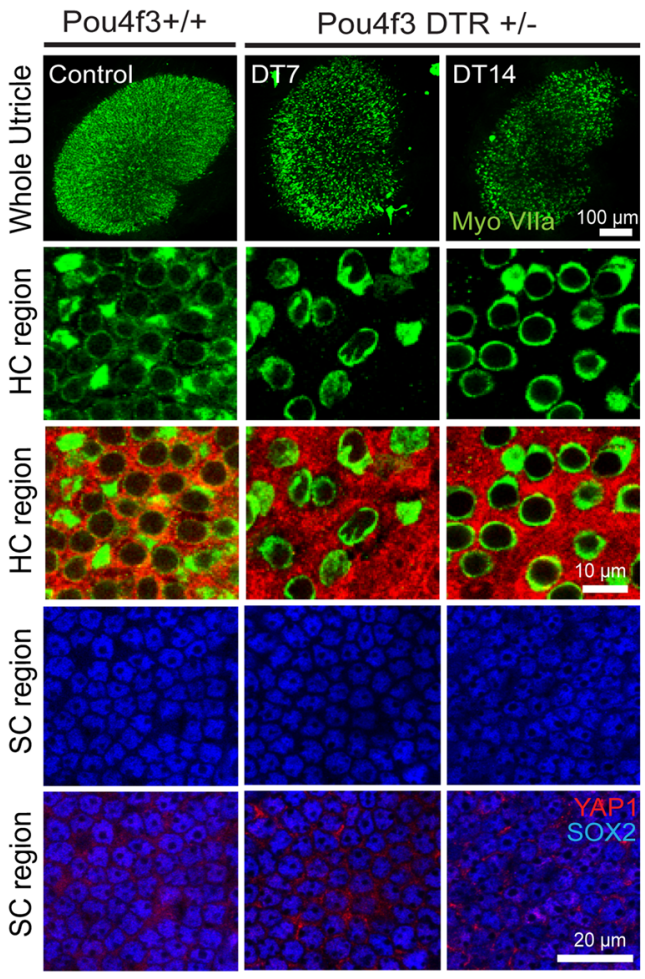

B

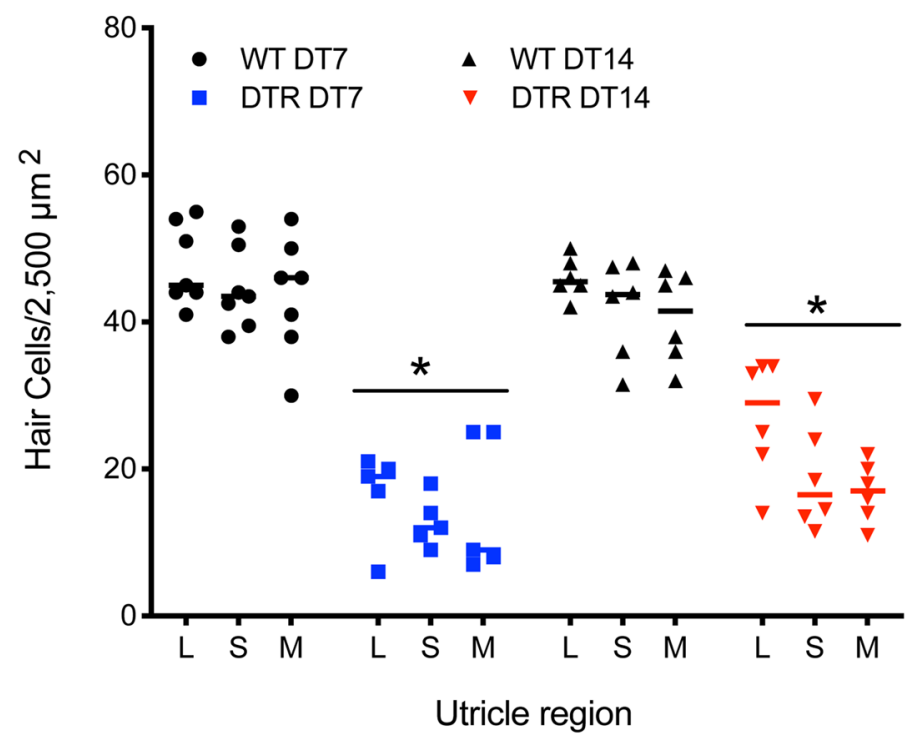

Figure 4. Nuclear translocation of YAP1 was not observed after diphtheria toxin (DT)-mediated hair cell lesions. (A) Adult Pou4f3 + / + and Pou4f3 + /DTR mice were injected with a single dose of DT (25 ng/g i.p). After 7 (DT7) or 14 (DT14) days recovery, utricles were collected, fixed and immunolabeled for myosin VIIa (green), SOX2 (blue) and YAP1 (red). Confocal images of wholemount utricles from Pou4f3 + / + (wild type control, at DT14) and Pou4f3 + /DTR at DT7 and at DT14 are shown in the top row. Images from the hair cell region and supporting cell region are shown in the second and third rows, and fourth, and fifth rows, respectively. Treatment with DT led to reduced hair cell numbers (green) and increased area of YAP1 positive (red) labeling in Pou4f3 + /DTR mice at DT14 and DT7, as compared to wild type controls. (B) Quantitative data on hair cell density after a single dose of DT ( $25 \mathrm{ng} / \mathrm{g}$ i.p). All data were obtained from 50 X $50 \mu \mathrm{m}$ regions within the lateral extrastriolar (L), striolar (S) and medial extrastriolar (M) regions of each utricle. There was a significant decrease in hair cell numbers at DT7 and DT14, compared to controls $(\mathrm{p}<0.0001)$. However, as shown in (A), this hair cell loss did not lead to YAP1 immunoreactivity in the nuclei of supporting cells. Data expressed as mean \pm SD. Statistical tests used two-way ANOVA followed by Tukey's post hoc test $\left({ }^{*} \mathrm{p}\right.$ value $<0.05$, relative to $\mathrm{P} 0)$. $\mathrm{N}=4-6$ utricle. 
Figure 5. Diphtheria toxin injection creates a large epithelial 'wound' in utricles of neonatal Pou4f3-DTR mice. (A) Pou4f3-DTR mice received a single $5 \mathrm{ng} / \mathrm{gm}$ injection of DT at P5, which resulted in a large-scale loss of hair cells (myosin VIIa-green) and supporting cells, which was apparent after 5-7 days recovery (DT5/7). Such lesions were typically located in the central region of the utricle. (B) Neonatal Pou4f3-DTR mice were allowed to recover for 5, 7, 14, 28, 56 days (DT5, DT7, DT14, DT28 and DT56) after DT treatment at P5. Wounds in the sensory epithelium (phalloidin-blue, myosin VIIa-red) were observed at 5 and 7 days after DT treatment, but were repaired by 14 days. (C,D) Quantitative analysis of cell density and epithelial repair as a function of recovery time. Data are expressed as mean \pm SD and analyzed with two-way ANOVA test $\left({ }^{\star} p\right.$ value $\left.<0.05\right)$. $\mathrm{N}=4-6$ utricle. (E,E’) Low magnification image of the utricle from a Pou4f3-DTR mouse that received DT at P5 and was allowed to recover for seven days. Note that hair cells (red, myosin VIIa) and cell-cell junctions (blue, phalloidin) are missing from a large region of the epithelium. The border of the epithelial lesion possessed a continuous ring of filamentous actin (arrows). (E") Image of utricle after 14 days recovery, showing the closure of the epithelial 'wound'. (E', E'”') At seven days after DT injection, the shapes of many supporting cells indicated changes in the mechanical tension within the epithelium (arrows). However, YAP1 (green) was not observed in supporting cell nuclei (gray).

dimerizes with DNA-binding TEAD family proteins, and initiates changes in gene expression ${ }^{25}$. Nuclear translocation of YAP1 occurs after cellular injury or mechanical stress and can induce proliferation and regeneration. We observed immunoreactivity for YAP1 in the cytoplasm of supporting cells in utricles from both mice and chickens. Hair cell injury to the chick utricle resulted in nuclear translocation of YAP1, but we did not observe this response in the mouse utricle, even after severe epithelial injury. These results, which are consistent with findings recently reported by other investigators ${ }^{34-37}$, suggest that the lack of YAP1 signaling following hair cell damage may be one factor that limits the regenerative ability of the mammalian ear.

One key regulator of YAP1 is the Hippo pathway, a highly-conserved signaling network that modulates cell growth and division in numerous tissues and organ systems ${ }^{38}$. Activation of the upstream components of the Hippo pathway determine the phosphorylation status of cytoplasmic YAP1. Phosphorylated YAP1 is targeted for degradation and does not enter the nucleus. However, activation of the upstream Hippo pathway prevents YAP1 phosphorylation, permitting YAP1 nuclear translocation, binding to TEAD family transcriptional coactivators, and modification of gene expression. Notably, mechanical forces exerted on cells can also influence YAP1 phosphorylation, although it is not clear whether such forces act via the Hippo pathway or by other signaling mechanisms ${ }^{39}$.

Our results indicate that hair cell damage to the mouse utricle damage does not promote nuclear translocation of YAP1, but we did observe nuclear entry of YAP1 after utricles were removed from mice and placed in culture. This response was rapid and transient. Nuclear immunoreactivity for YAP1 was noted after two hours in vitro, but was not present after $24 \mathrm{~h}$ of culture. The processes of dissection and placement in organotypic culture are likely to dramatically alter the mechanical environment of the utricle, and the observed changes in YAP1 are consistent with the notion that mechanical forces influence YAP1 localization ${ }^{26,40-43}$. Hair cell loss or epithelial wounding are also likely to cause local changes in cellular tension, but it is possible that large-scale mechanical disruptions of the utricular epithelium are required for activation of YAP1 signaling. Our data from the cultured explants also indicate that YAP1 translocation occurs at very short intervals after changes in epithelial mechanics (i.e., within $2 \mathrm{~h}$ of dissection). YAP1 may also translocate to the nuclei of supporting cells at similarly short times after hair cell loss, but the temporal resolution of our methods does not permit us to resolve this issue. However, hair cell lesions created by neomycin treatment or by DT injection in Pou4f3-huDTR mice are not synchronized, and can require 2-7 days to fully manifest ${ }^{12,31,32}$. If hair cell loss caused short-term nuclear YAP1 in adjoining supporting cells, we would have expected to observe some elevation in nuclear YAP1 in utricles fixed at various times after neomycin or DT-mediated damage. Our results are also consistent with another recent study, which failed to observe injury-evoked nuclear transport of YAP1 in the mouse utricle ${ }^{34}$.

In addition to observing YAP1 in supporting cells, we also observed cytoplasmic YAP1 immunoreactivity in a subset of developing hair cells in the mouse utricle. Such cells were only observed during the first postnatal week, and they possessed Sox2-labeled nuclei (a marker of type II identity ${ }^{44,45}$ ) and were concentrated in the lateral portion of the sensory epithelium. Prior studies have shown that most type II hair cells of the mouse utricle differentiate during the first postnatal week and are disproportionally added to the lateral region of the sensory epithelium $^{28-30}$. It is likely that the YAP1-labeled hair cells had recently differentiated from YAP1-expressing precursors and were undergoing differentiation as type II hair cells. This suggestion is consistent with single cell RNA seq data obtained from utricles of newborn mice ${ }^{45}$, which indicate that YAP1 is expressed by immature hair cells (McInturff et al. data available at umgear.org). However, interactions between YAP1 and Sox 2 are involved in the maintenance of stemness and fate determination in different types of stem cells ${ }^{46-49}$, and it is possible that YAP1 and Sox 2 interactions may serve some unidentified role in the process of hair cell production and differentiation.

One unexpected observation reported here is the presence of a large epithelial 'wound' in the utricles of neonatal Pou4f3-huDTR mice after a single $5 \mathrm{ng} / \mathrm{gm}$ injection of DT. This treatment reliably caused extensive loss of both hair cells and supporting cells, resulting in a large opening in the sensory epithelium. Such lesions were not observed in the cristae of the semicircular canals or in the cochlea; in those sensory organs, DT injection caused a selective loss of hair cells, a pattern which resembled that reported after DT treatment of mature Pou4f3-huDTR mice ${ }^{12,31,32}$ (Warchol, unpublished data). The cellular events responsible for this epithelial wound are not clear. It is possible that some supporting cells in the neonatal utricle transiently express Pou4f3 during early postnatal development, leading to co-expression of the DT receptor in those cells. Also, the E-cadherinmediated cellular junctions in the neonatal utricle are not fully mature at $\mathrm{P} 5^{50}$, so the epithelium may not be able 
A
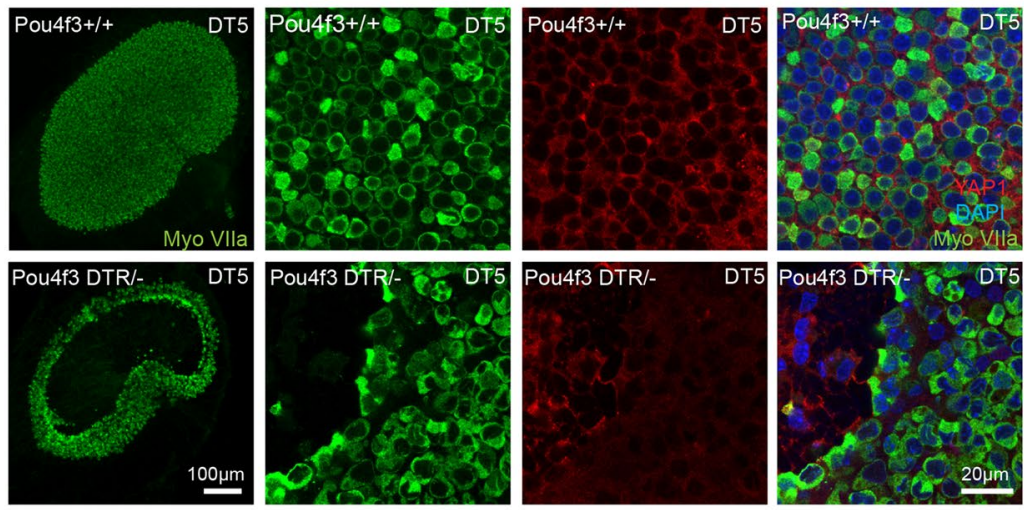

B
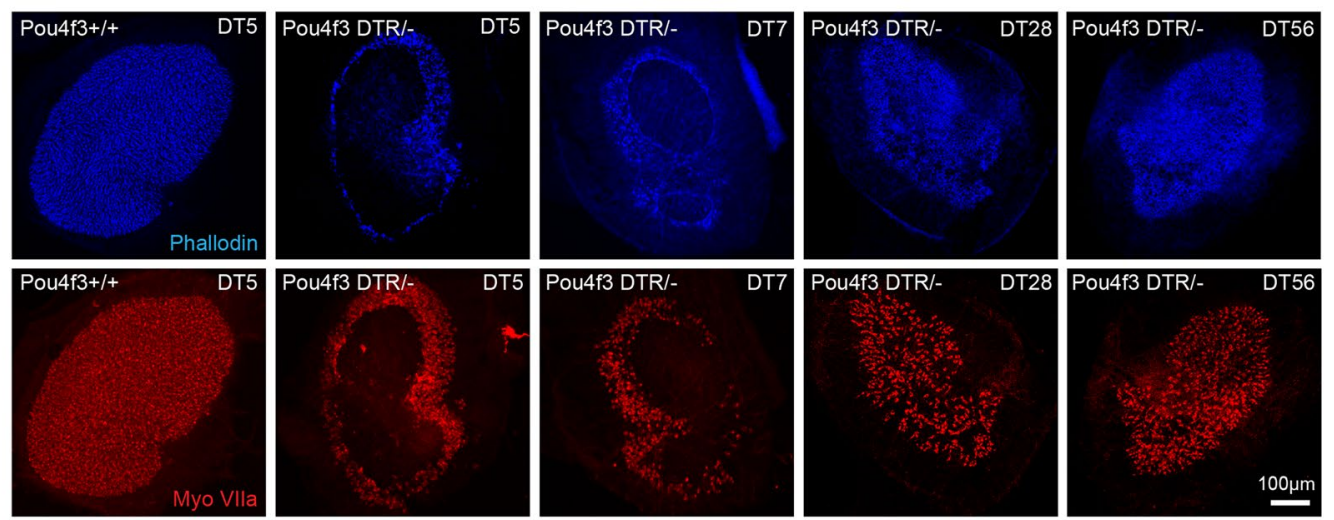

C

E
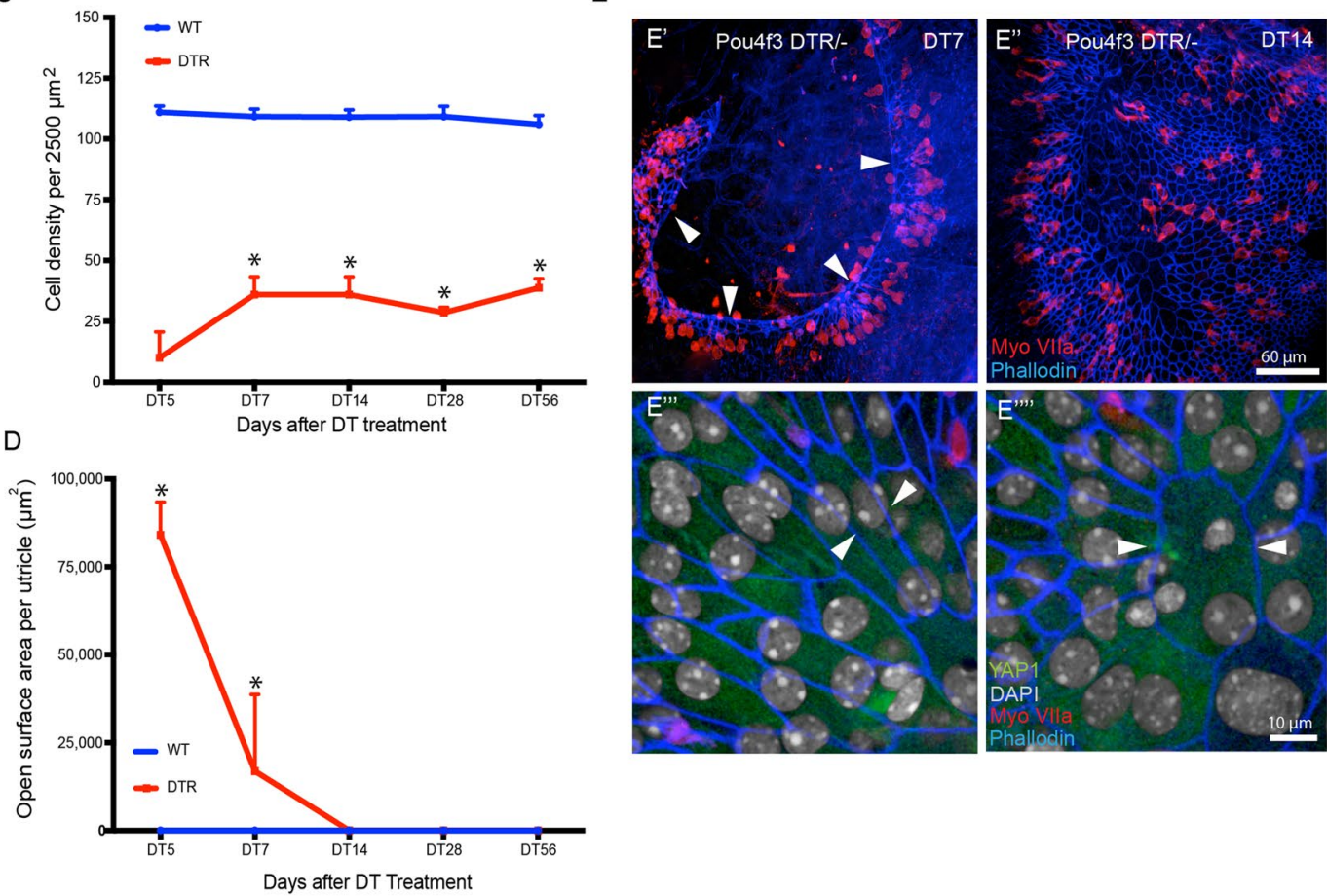
to maintain integrity after a high level of DT-mediated hair cell death. Finally, the dose of DT used in the present study $(5 \mathrm{ng} / \mathrm{g})$ was slightly higher than the dose used in prior studies ${ }^{51}$. In any case, we found that these lesions closed spontaneously within seven days, similar to the pattern of closure observed after in vitro puncture wounds in the utricles of embryonic mice ${ }^{52}$. Such large epithelial wounds are likely to have caused considerable disruption in the mechanical environment experienced by the remaining cells. Further changes in cellular tension would also occur during the process of wound closure. Notably, however, none of these changes was sufficient to cause increases in nuclear translocation of YAP1. Some degree of YAP1 translocation has been observed following lesioning of the sensory epithelium and stromal tissue of the neonatal mouse utricle ${ }^{26,34}$, but the types of lesions employed in these studies (direct tissue injury caused by a fine needle or micropunch), may have generated considerably more mechanical force on the sensory epithelium than was created by our DT lesion.

Finally, our data suggest important functional differences in YAP1 signaling in the utricles of birds vs. mammals. In agreement with another recent study ${ }^{34}$, we observed cytoplasmic YAP1 in all supporting cells of the chick utricle, and nuclear YAP1 was observed in supporting cell nuclei after hair cell lesions in vitro. We also noted a similar YAP1 response in response to in vivo hair cell lesions, created by systemic treatment with streptomycin. Finally, disruption of YAP1 signaling by treatment with verteporfin resulted in a reduction in regenerative proliferation. Together, these observations suggest that YAP1 may serve a role in the initiation of regeneration in the avian inner ear. Both our results and others ${ }^{34}$ indicate minimal changes in YAP1 localization after ototoxic injury to the utricles of neonatal or mature mice, so it is possible that differences in YAP1 signaling may partially explain the differing regenerative abilities of the avian vs. mammalian inner ear.

\section{Methods}

Animals. Studies used mice of both sexes on C57BL/6 or CD1 backgrounds. Some studies also used Pou4f3huDTR transgenic mice, in which the human form of the diphtheria toxin receptor (hu-DTR) gene is expressed under the control of the Pou4f3 transcription factor promoter ${ }^{12,31,53}$. Chickens were hatched from fertile eggs (Charles River SPAFAS) and maintained in heated brooders until used in experiments. Mice and chickens were housed in the animal facilities of Washington University in Saint Louis, and were maintained on a 12-h/daynight light cycle with open access to food and water. All experimental protocols involving animals were approved and performed in accordance with relevance guidelines and regulations of the Institutional Animal Care and Use Committee (IACUC) of Washington University, School of Medicine, in Saint Louis, MO.

Experiments with mice. Genotyping. Genotyping protocol for identification of Pou $43^{\mathrm{DTR} /+}$ and Pou $4 \mathrm{f}^{+/+}$was similar to Tong et al. ${ }^{31}$. Briefly, DNA was extracted from tails using ethanol precipitation. PCR was used to amplify the targeted allele (Quick-Load Taq 2X Master Mix, New England Biolabs Inc), using the following primers (at $0.4 \mu \mathrm{M}$ ): Pou 4 3 (WT) Forward 5' CAC TTG GAG CGC GGA GAG CTA G; Pou4f3 (mutant) Reverse 5' CCG ACG GCA GCA GCT TCA TGG TC. PCR was performed using the following reaction conditions: $95^{\circ} \mathrm{C}$ for $5 \mathrm{~min} ; 95^{\circ} \mathrm{C}$ for $30 \mathrm{~s}, 59^{\circ} \mathrm{C}$ for $30 \mathrm{~s}, 72^{\circ} \mathrm{C}$ for $1 \mathrm{~min}, 30$ cycles; $72^{\circ} \mathrm{C}$ for $7 \mathrm{~min} ; 4^{\circ} \mathrm{C}$ infinity. PCR products were run on 1.5-2\% agarose gel containing $1 \mu \mathrm{l} / \mathrm{ml}$ SYBR safe DNA gel stain (expected band $\sim 150$ bps) (ThermoFisher).

Hair cell ablation. Mice received a single dose of Diphtheria toxin (DT, Sigma), which was administered intramuscularly (i.m., $5 \mathrm{ng} / \mathrm{gm}$ ) in the thigh region of the hind leg of P5 mice and intraperitoneally (i.p., $25 \mathrm{ng} / \mathrm{gm}$ ) in 4-6-week adult mice. Using identical methods, DT was also administered to wild type (WT) littermates, which served as controls. Mice were allowed to survive for $5,7,14,28$, or 56 days after DT injections.

Utricle explant culture. Mice were euthanized at P15 or P28 and temporal bones were removed and placed in tissue culture medium under sterile condition. Utricles were isolated and otoconia were gently removed from the surface using fine forceps. Utricles were cultured free-floating and/or attached to Matrigel-coated surfaces in $1 \mathrm{~cm}$ diameter wells (MatTek). Each well contained $100 \mu \mathrm{l}$ of Medium 199 with Earle's salts, $2200 \mathrm{mg} / \mathrm{L}$ sodium bicarbonate, $0.69 \mathrm{~mm}$ l-glutamine, $25 \mathrm{~mm}$ HEPES (Gibco), supplemented with 10\% FBS and $10 \mu \mathrm{g} / \mathrm{ml} \mathrm{Cipro-}$ floxacin. Utricles were cultured at $37^{\circ} \mathrm{C}$ in a $5 \% \mathrm{CO} 2 / 95 \%$ air environment.

Immunohistochemistry. For in vivo samples, mice were euthanized with Fatal Plus and isolated temporal bones were fixed with $4 \%$ paraformaldehyde (PFA) in $0.1 \mathrm{M}$ phosphate buffer (PB) overnight at $4{ }^{\circ} \mathrm{C}$. Cultured utricles were fixed for 1-2 $\mathrm{h}$ with $4 \%$ paraformaldehyde in $\mathrm{PB}$ at room temperature. After fixation, utricles were washed $3 \times(5 \mathrm{~min}$ each) in PBS and then processed for whole mount immunohistochemistry. Rabbit polyclonal antiMyosin VI antibody (catalog \#25-6791, Proteus BioSciences, 1:500) was used to label hair cells, Goat polyclonal anti-Sox2 antibody (catalog \# sc-17319, Santa Cruz Biotechnology, 1:100) was used to label supporting cells ${ }^{54}$, and two different YAP1 antibodies were used to characterize YAP1 expression patterns: mouse monoclonal antiYAP1 antibody (catalog \# sc-101199,1:50) and rabbit monoclonal anti-YAP1 antibody (catalog \# 14074S, Cell Signaling, 1:100). To prevent non-specific binding of the antibodies, samples were incubated in a blocking solution consisting of $5 \%$ normal horse serum/0.2\% Triton X-100 in PBS for $1 \mathrm{~h}$ at room temperature. Samples were then incubated overnight in primary antibodies prepared in PBS with $2 \%$ horse serum and $0.2 \%$ Triton X-100 at $4{ }^{\circ} \mathrm{C}$. Samples were then rinsed $3 \times(5 \mathrm{~min}$ each) in PBS and incubated for $2-3 \mathrm{~h}$ in secondary antibodies (conjugated to Alexa-488, Alexa-568, and Alexa 647, Life Technologies, 1:500) at room temperature. All secondaries were prepared in PBS with $2 \%$ horse serum and $0.2 \%$ Triton X-100. Filamentous actin was labeled with Alexa Fluor 647 Phalloidin and Alexa Fluor 488 (Invitrogen, catalog \#A22287, and \#A12379, 1:200), and cell nuclei were labeled with DAPI (catalog \#D9542, Sigma-Aldrich, $1 \mu \mathrm{g} / \mathrm{ml}$ ). All samples were rinsed $3 \times(5 \mathrm{~min}$ each) in PBS. Samples were mounted in glycerol: PBS (9:1) solution and coverslipped on glass slides. 

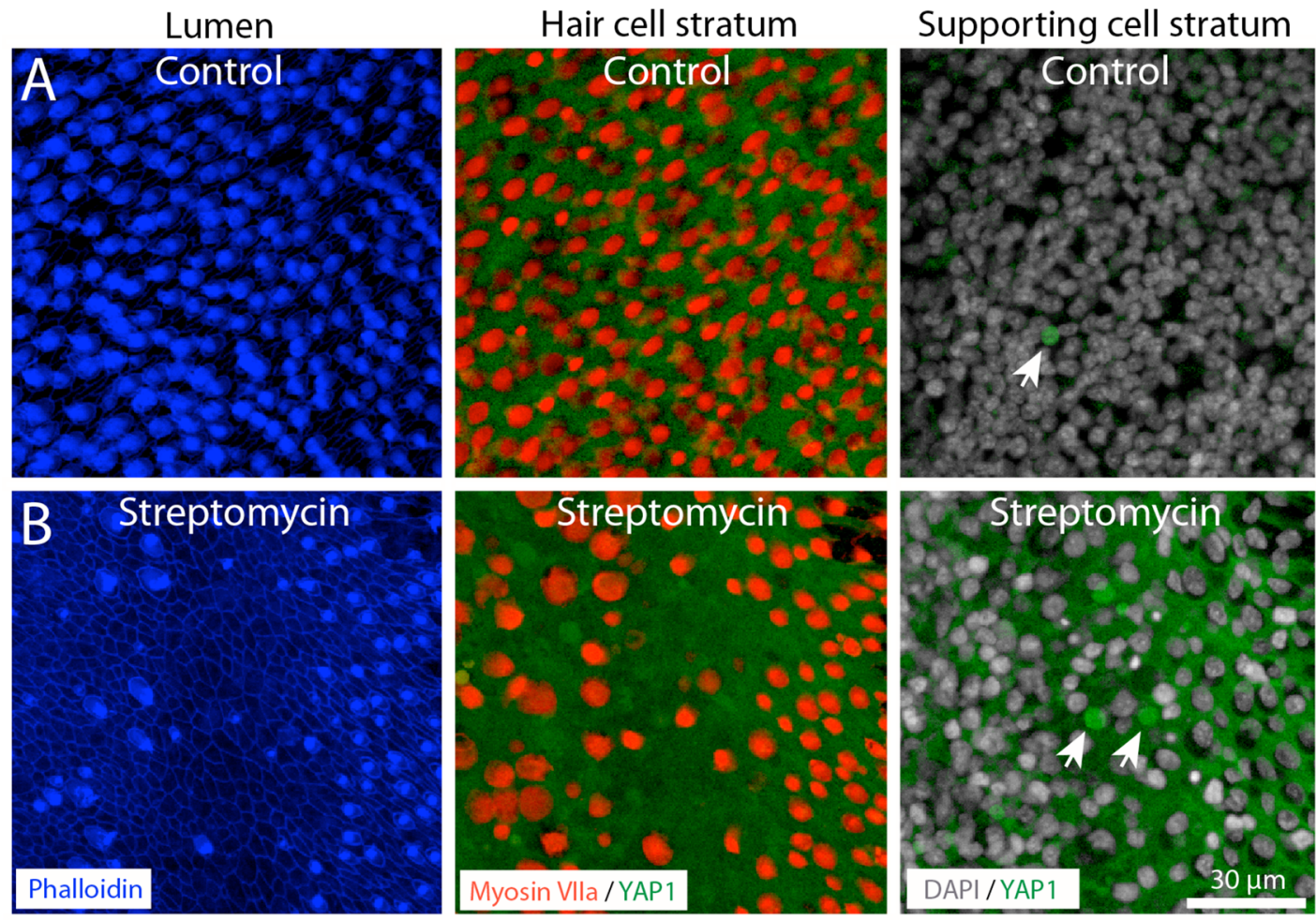

C

D
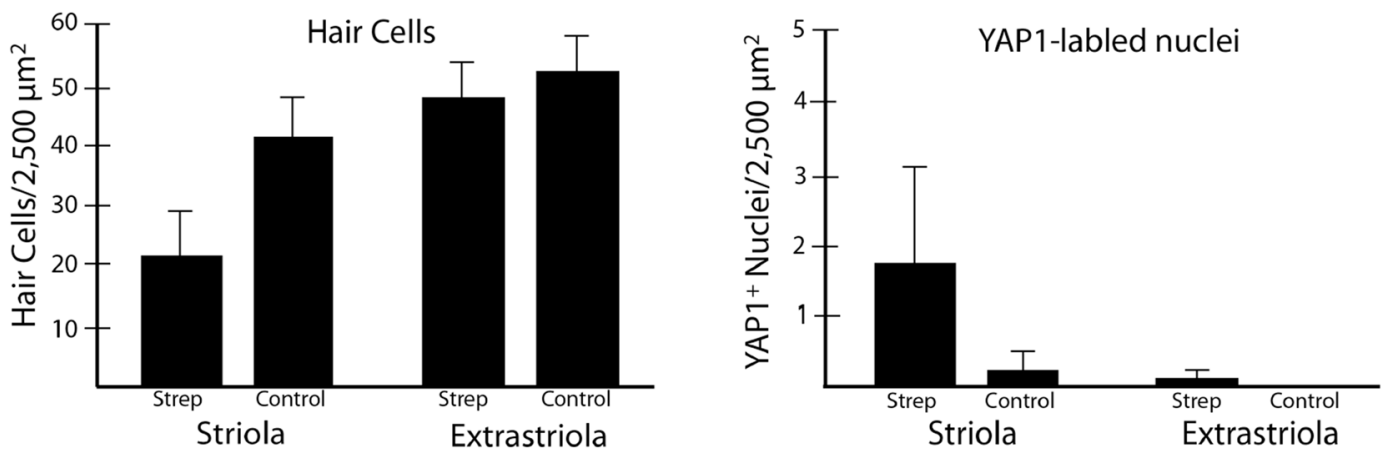

Figure 6. Localization of YAP1 in the chick utricle. (A) Labeling of an undamaged utricle with phalloidin (blue) shows numerous stereocilia (left) and hair cells (red, labeled for myosin VIIa) surrounded by YAP1expressing supporting cells (green) (middle). We also observed a few supporting cell nuclei with nuclear YAP1 (arrow) in undamaged (control) utricles. (B) Three days of systemic treatment with streptomycin $(1200 \mathrm{mg} / \mathrm{kg}$ ) caused a partial loss of hair cells that was limited to the striolar region. This region of hair cell loss also contained increased numbers of supporting cells with nuclear immunoreactivity for YAP1. (C,D) Quantification of hair cells and YAP-labeled nuclei in streptomycin-treated and control utricles. Streptomycin treatment resulted in hair cell loss and increased YAP1-labeled nuclei in the striolar region ( $t$-test, $p=0.016)$. In contrast, the extrastriolar region was not affected by the streptomycin treatment $(\mathbf{C})$ and did not contain enhanced numbers of YAP1-labeled nuclei (D).

Studies involving chickens. Hatchling chicks were housed in Washington University animal facilities as described above. Studies conducted in vivo used chickens at $\sim 4$-week post-hatch. Chickens received injections of streptomycin sulfate $(1200 \mathrm{mg} / \mathrm{kg}$, i.m.) once/day for three consecutive days. Chickens were allowed to recover for $24 \mathrm{~h}$ after the last injection and were then euthanized by $\mathrm{CO}_{2}$ inhalation. Utricles were quickly removed and fixed for $30 \mathrm{~min}$ in $4 \%$ paraformaldehyde (in $0.1 \mathrm{M} \mathrm{PB}$ ). Specimens were rinsed $3 \times$ and processed for immunohistochemical labeling, using methods described above. Controls consisted of age-matched (clutchmate) chickens that did not receive streptomycin.

Organotypic cultures of chick utricles were prepared following previously described methods ${ }^{33}$. Briefly, chicks (10-20 days post-hatch) were euthanized via $\mathrm{CO}_{2}$ inhalation and quickly decapitated. The lower jaw and skin covering the head were removed and heads were immersed for 5-10 $\mathrm{min}$ in $70 \% \mathrm{EtOH}$. All subsequent work was conducted under aseptic conditions. Utricles were removed from temporal bones and transferred to chilled Medium-199 (with Hanks salts and 25 mM HEPES; Thermo-Fisher). The otoconia were removed and isolated sensory organs were placed 
A
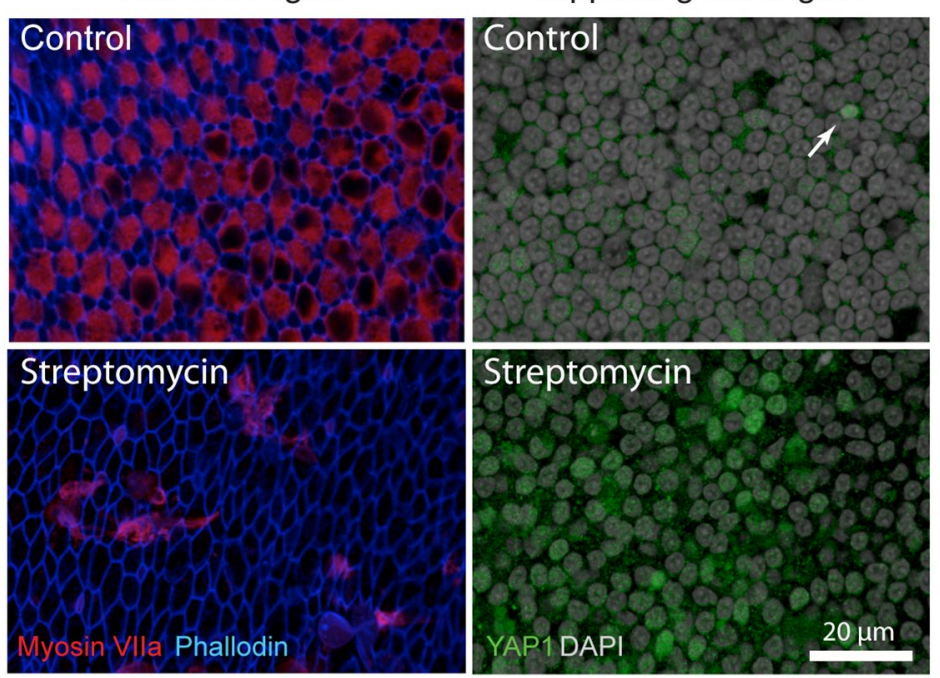

B

Supporting cell region

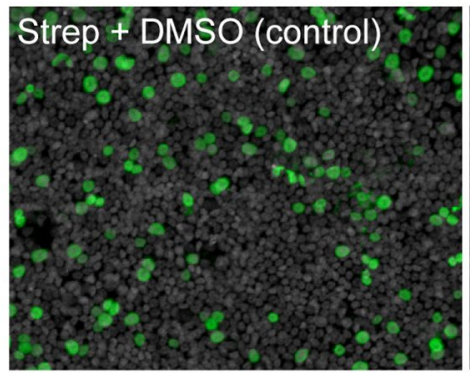

Supporting cell region

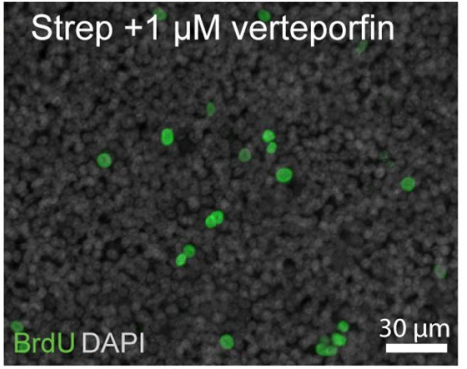

Figure 7. YAP1 response to ototoxic injury in organotypic cultures of the chick utricle. (A) Left: Utricles that were maintained in culture for $24 \mathrm{~h}$ in $1 \mathrm{mM}$ streptomycin showed extensive loss of hair cells (blue, phalloidin), when compared to control cultures. Right: This hair cell lesion was accompanied by enhanced nuclear translocation of YAP1 (green) in remaining supporting cells. (B) Some utricles were allowed to recover for $48 \mathrm{~h}$ after streptomycin treatment, and proliferating cells were labeled with a $24 \mathrm{~h}$ pulse of BrdU (green). Numerous BrdU-labeled cells (green) were observed in streptomycin-injured utricles. However, addition of verteporfin caused a reduction in proliferating cells $(\mathrm{p}=0.0008$, see text for details).

in $1 \mathrm{~cm}$ culture wells (Mat Tek, Ashland MA) that contained $100 \mu \mathrm{l}$ of Medium-199 (with Earles salts, $2200 \mathrm{mg} / \mathrm{L}$ sodium bicarbonate, $0.69 \mathrm{mM}$ L-glutamine and $25 \mathrm{mM}$ HEPES) supplemented with $1 \%$ fetal bovine serum (FBS). Some utricles also received streptomycin, for a final concentration of $1 \mathrm{mM}$. Utricles were incubated at $37^{\circ} \mathrm{C}$ a humid $5 \% \mathrm{CO}_{2} / 95 \%$ air environment. After $24 \mathrm{~h}$ in vitro, specimens were rinsed $3 \times$ with fresh medium and given $100 \mu \mathrm{l}$ of Medium-199/1\%FBS, that also contained $1.0 \mu \mathrm{M}$ verteporin (Sigma) or 0.1\% DMSO (vehicle). Cultures were maintained in these media for an additional $48 \mathrm{~h}$ and $\mathrm{BrdU}(3 \mu \mathrm{g} / \mathrm{ml})$ was added for the final $24 \mathrm{~h}$ in vitro. Specimens were fixed for $30 \mathrm{~min}$ in 4\% PFA and processed for immunocytochemical labeling of BrdU (protocol in Slattery and Warchol $)^{55}$. Nuclei were counterstained with DAPI. Specimens were visualized as wholemounts and confocal images were obtained from three $100 \times 100 \mu \mathrm{m}$ regions in the extrastriolar portion of each utricle.

Cellular imaging and analyses. Fluorescent images were obtained using a Zeiss LSM 700 confocal microscope. For all specimens, Z-series images were obtained at $10 \times(\sim 4$.5-micron $\mathrm{z}$-step size), $20 \times(1$ or 2 -micron $\mathrm{z}$-step size $)$, or $63 \times(0.5$ or 1.0 -micron $\mathrm{Z}$-step size $)$ objectives. Images were processed and analyzed using Volocity $3 \mathrm{D}$ image analysis software (version 6.3, PerkinElmer) and Fiji (ImageJ2.0) (National Institutes of Health) and Adobe illustrator CS5.1.

Hair cell and supporting cell counts. Cell quantification was performed from $63 \times$ images using Fiji software (ImageJ2.0, National Institutes of Health). For all cell counts, lateral extra striolar, striolar and medial extra striolar region were selected per utricle samples. The Cell Counter plug-in was used for all cell counts. For hair cell counts, a grid of $1000 \mu \mathrm{m}^{2}$ or $2500 \mu \mathrm{m}^{2}$ was applied to the Z-stack images. Hair cells were identified by strong cytoplasmic immunolabeling for myosin Vlla. All hair cells were manually counted within the designed area of complete z-stack. For supporting cell counts, a grid of $10,000 \mu \mathrm{m}^{2}$ was applied to the Z-stack images. Supporting cells were identified by strong nuclear immunolabeling for Sox-2 protein. All supporting cells were manually counted within the designed area of complete z-stacks. Fiji software (ImageJ2.0) is also used to measure the surface area in each utricle. 
Statistical analysis. All the data analysis and statistics were carried out using GraphPad Prism version 6.0d. Data are presented as mean \pm SD. Student's t-tests or analyses of variance (ANOVA) followed by Tukey's or Bonferroni's post hoc tests were applied, as appropriate. Results were considered statistically significant when $\mathrm{p}<0.05$.

Received: 13 May 2020; Accepted: 12 November 2020

Published online: 25 January 2021

\section{References}

1. Raphael, Y. \& Altschuler, R. A. Structure and innervation of the cochlea. Brain Res. Bull. 60, 397-422. https://doi.org/10.1016/ s0361-9230(03)00047-9 (2003).

2. Bohne, B. A. Healing of the noise-damaged inner ear. In Hearing and Davis: Essays Honoring Hallowell Davis (eds Hirsh, S. K. et al.) 85-96 (Washington University Press, St. Louis, 1976).

3. Hawkins, J. E. Jr., Johnsson, L. G., Stebbins, W. C., Moody, D. B. \& Coombs, S. L. Hearing loss and cochlear pathology in monkeys after noise exposure. Acta Otolaryngol. 81, 337-343. https://doi.org/10.3109/00016487609119971 (1976).

4. Cotanche, D. A. Regeneration of hair cell stereociliary bundles in the chick cochlea following severe acoustic trauma. Hear. Res. 30, 181-195. https://doi.org/10.1016/0378-5955(87)90135-3 (1987).

5. Corwin, J. T. \& Cotanche, D. A. Regeneration of sensory hair cells after acoustic trauma. Science 240, 1772-1774. https://doi.org/ $10.1126 /$ science.3381100 (1988).

6. Ryals, B. M. \& Rubel, E. W. Hair cell regeneration after acoustic trauma in adult Coturnix quail. Science 240, 1774-1776. https:// doi.org/10.1126/science.3381101 (1988).

7. Weisleder, P. \& Rubel, E. W. Hair cell regeneration after streptomycin toxicity in the avian vestibular epithelium. J. Comp. Neurol. 331, 97-110. https://doi.org/10.1002/cne.903310106 (1993).

8. Burns, J. C. \& Stone, J. S. Development and regeneration of vestibular hair cells in mammals. Semin. Cell. Dev. Biol. 65, 96-105. https://doi.org/10.1016/j.semcdb.2016.11.001 (2017).

9. Warchol, M. E. Sensory regeneration in the vertebrate inner ear: Differences at the levels of cells and species. Hear. Res. 273, 72-79. https://doi.org/10.1016/j.heares.2010.05.004 (2011).

10. Adler, H. J. \& Raphael, Y. New hair cells arise from supporting cell conversion in the acoustically damaged chick inner ear. Neurosci. Lett. 205, 17-20. https://doi.org/10.1016/0304-3940(96)12367-3 (1996).

11. Baird, R. A., Steyger, P. S. \& Schuff, N. R. Mitotic and nonmitotic hair cell regeneration in the bullfrog vestibular otolith organs. Ann. N. Y. Acad. Sci. 781, 59-70. https://doi.org/10.1111/j.1749-6632.1996.tb15693.x (1996).

12. Golub, J. S. et al. Hair cell replacement in adult mouse utricles after targeted ablation of hair cells with diphtheria toxin. J. Neurosci. 32, 15093-15105. https://doi.org/10.1523/JNEUROSCI.1709-12.2012 (2012).

13. Denans, N., Baek, S. \& Piotrowski, T. Comparing sensory organs to define the path for hair cell regeneration. Annu. Rev. Cell. Dev. Biol. 35, 567-589. https://doi.org/10.1146/annurev-cellbio-100818-125503 (2019).

14. Samarajeewa, A., Jacques, B. E. \& Dabdoub, A. Therapeutic potential of Wnt and notch signaling and epigenetic regulation in mammalian sensory hair cell regeneration. Mol. Ther. 27, 904-911. https://doi.org/10.1016/j.ymthe.2019.03.017 (2019).

15. Kelly, M. C., Chang, Q., Pan, A., Lin, X. \& Chen, P. Atoh1 directs the formation of sensory mosaics and induces cell proliferation in the postnatal mammalian cochlea in vivo. J. Neurosci. 32, 6699-6710. https://doi.org/10.1523/JNEUROSCI.5420-11.2012 (2012).

16. Atkinson, P. J., Wise, A. K., Flynn, B. O., Nayagam, B. A. \& Richardson, R. T. Hair cell regeneration after ATOH1 gene therapy in the cochlea of profoundly deaf adult guinea pigs. PLoS ONE 9, e102077. https://doi.org/10.1371/journal.pone.0102077 (2014).

17. Walters, B. J. et al. In vivo interplay between p27(Kip1), GATA3, ATOH1, and POU4F3 converts non-sensory cells to hair cells in adult mice. Cell. Rep. 19, 307-320. https://doi.org/10.1016/j.celrep.2017.03.044 (2017).

18. Sayyid, Z. N., Wang, T., Chen, L., Jones, S. M. \& Cheng, A. G. Atohl directs regeneration and functional recovery of the mature mouse vestibular system. Cell. Rep. 28, 312-324. https://doi.org/10.1016/j.celrep.2019.06.028 (2019).

19. Moya, I. M. \& Halder, G. Hippo-YAP/TAZ signalling in organ regeneration and regenerative medicine. Nat. Rev. Mol. Cell. Biol. 20, 211-226. https://doi.org/10.1038/s41580-018-0086-y (2019).

20. Loh, S. L. et al. Zebrafish yap1 plays a role in differentiation of hair cells in posterior lateral line. Sci. Rep. 4, 4289. https://doi.org/ $10.1038 /$ srep04289 (2014).

21. Su, T. et al. Two-signal requirement for growth-promoting function of Yap in hepatocytes. Elife https://doi.org/10.7554/eLife.02948 (2015).

22. Wang, Y. et al. Comprehensive molecular characterization of the hippo signaling pathway in cancer. Cell. Rep. 25, $1304-1317$. https://doi.org/10.1016/j.celrep.2018.10.001 (2018).

23. Camargo, F. D. et al. YAP1 increases organ size and expands undifferentiated progenitor cells. Curr. Biol. 17, 2054-2060. https:// doi.org/10.1016/j.cub.2007.10.039 (2007).

24. Dong, J. et al. Elucidation of a universal size-control mechanism in Drosophila and mammals. Cell 130, 1120-1133. https://doi. org/10.1016/j.cell.2007.07.019 (2007).

25. Panciera, T., Azzolin, L., Cordenonsi, M. \& Piccolo, S. Mechanobiology of YAP and TAZ in physiology and disease. Nat. Rev. Mol. Cell. Biol. 18, 758-770. https://doi.org/10.1038/nrm.2017.87 (2017).

26. Gnedeva, K., Jacobo, A., Salvi, J. D., Petelski, A. A. \& Hudspeth, A. J. Elastic force restricts growth of the murine utricle. Elife https:// doi.org/10.7554/eLife.25681 (2017).

27. Gnedeva, K. et al. Organ of corti size is governed by Yap/Tead-mediated progenitor self-renewal. Proc. Natl. Acad. Sci. USA. 117, 13552-13561. https://doi.org/10.1073/pnas.2000175117 (2020).

28. Burns, J. C., Cox, B. C., Thiede, B. R., Zuo, J. \& Corwin, J. T. In vivo proliferative regeneration of balance hair cells in newborn mice. J. Neurosci. 32, 6570-6577. https://doi.org/10.1523/JNEUROSCI.6274-11.2012 (2012).

29. Burns, J. C., On, D., Baker, W., Collado, M. S. \& Corwin, J. T. Over half the hair cells in the mouse utricle first appear after birth, with significant numbers originating from early postnatal mitotic production in peripheral and striolar growth zones. J. Assoc. Res. Otolaryngol. 13, 609-627. https://doi.org/10.1007/s10162-012-0337-0 (2012).

30. Warchol, M. E., Massoodnia, R., Pujol, R., Cox, B. C. \& Stone, J. S. Development of hair cell phenotype and calyx nerve terminals in the neonatal mouse utricle. J. Comp. Neurol. 527, 1913-1928. https://doi.org/10.1002/cne.24658 (2019).

31. Tong, L. et al. Selective deletion of cochlear hair cells causes rapid age-dependent changes in spiral ganglion and cochlear nucleus neurons. J. Neurosci. 35, 7878-7891. https://doi.org/10.1523/JNEUROSCI.2179-14.2015 (2015).

32. Kaur, T. et al. Fractalkine signaling regulates macrophage recruitment into the cochlea and promotes the survival of spiral ganglion neurons after selective hair cell lesion. J. Neurosci. 35, 15050-15061. https://doi.org/10.1523/JNEUROSCI.2325-15.2015 (2015).

33. Warchol, M. E. \& Montcouquiol, M. Maintained expression of the planar cell polarity molecule Vangl2 and reformation of hair cell orientation in the regenerating inner ear. J. Assoc. Res. Otolaryngol. 11, 395-406. https://doi.org/10.1007/s10162-010-0209-4 (2010).

34. Rudolf, M. A. et al. YAP mediates hair cell regeneration in balance organs of chickens, but LATS kinases suppress its activity in mice. J. Neurosci. 40, 3915-3932. https://doi.org/10.1523/JNEUROSCI.0306-20.2020 (2020). 
35. Kozlowski, M., Rudolf, M. A. \& Corwin, J. T. EGF and a GSK3 inhibitor deplete junctional E-cadherin and stimulate proliferation in the mature mammalian ear. J. Neurosci. 40, 2618-2632. https://doi.org/10.1523/JNEUROSCI.2630-19.2020 (2020).

36. Ye, Z. et al. Yap-lin28a axis targets let7-Wnt pathway to restore progenitors for initiating regeneration. Elife https://doi.org/10. 7554/eLife.55771 (2020).

37. Xia, M., Chen, Y., He, Y., Li, H. \& Li, W. Activation of the RhoA-YAP- $\beta$-catenin signaling axis promotes the expansion of inner ear progenitor cells in 3D culture. Stem Cells 38, 860-874. https://doi.org/10.1002/stem.3175 (2020).

38. Johnson, R. \& Halder, G. The two faces of Hippo: Targeting the Hippo pathway for regenerative medicine and cancer treatment. Nat. Rev. Drug Discov. 13, 63-79. https://doi.org/10.1038/nrd4161 (2014).

39. Elbediwy, A. et al. Enigma proteins regulate YAP mechanotransduction. J. Cell. Sci. https://doi.org/10.1242/jcs.221788 (2018).

40. Dupont, S. et al. Role of YAP/TAZ in mechanotransduction. Nature 474, 179-183. https://doi.org/10.1038/nature10137 (2011).

41. Sun, D. et al. YAP1 enhances cell proliferation, migration, and invasion of gastric cancer in vitro and in vivo. Oncotarget 7, 81062-81076. https://doi.org/10.18632/oncotarget.13188 (2016).

42. Das, A., Fischer, R. S., Pan, D. \& Waterman, C. M. YAP nuclear localization in the absence of cell-cell contact is mediated by a filamentous actin-dependent, myosin II- and phospho-YAP-independent pathway during extracellular matrix mechanosensing. J. Biol. Chem. 291, 6096-6110. https://doi.org/10.1074/jbc.M115.708313 (2016).

43. Meng, Z. et al. RAP2 mediates mechanoresponses of the Hippo pathway. Nature 560, 655-660. https://doi.org/10.1038/s41586018-0444-0 (2018).

44. Lu, J. et al. Increased type I and decreased type II hair cells after deletion of Sox 2 in the developing mouse utricle. Neuroscience 422, 146-160. https://doi.org/10.1016/j.neuroscience.2019.09.027 (2019).

45. McInturff, S., Burns, J. C. \& Kelley, M. W. Characterization of spatial and temporal development of Type I and Type II hair cells in the mouse utricle using new cell-type-specific markers. Biol.. Open https://doi.org/10.1242/bio.038083 (2018).

46. Frum, T., Murphy, T. M. \& Ralston, A. HIPPO signaling resolves embryonic cell fate conflicts during establishment of pluripotency in vivo. Elife https://doi.org/10.7554/eLife.42298 (2018).

47. Basu-Roy, U. et al. Sox2 antagonizes the Hippo pathway to maintain stemness in cancer cells. Nat. Commun. 6, 6411. https://doi. org/10.1038/ncomms7411 (2015).

48. Bora-Singhal, N. et al. YAP1 regulates OCT4 activity and SOX2 expression to facilitate self-renewal and vascular mimicry of stem-like cells. Stem Cells 33, 1705-1718. https://doi.org/10.1002/stem.1993 (2015).

49. Seo, E. et al. SOX2 regulates YAP1 to maintain stemness and determine cell fate in the osteo-adipo lineage. Cell. Rep. 3, $2075-2087$. https://doi.org/10.1016/j.celrep.2013.05.029 (2013).

50. Collado, M. S. et al. The postnatal accumulation of junctional E-cadherin is inversely correlated with the capacity for supporting cells to convert directly into sensory hair cells in mammalian balance organs. J. Neurosci. 31, 11855-11866. https://doi.org/10. 1523/JNEUROSCI.2525-11.2011 (2011).

51. Wang, T. et al. Uncoordinated maturation of developing and regenerating postnatal mammalian vestibular hair cells. PLoS Biol. 17, e3000326. https://doi.org/10.1371/journal.pbio.3000326 (2019).

52. Meyers, J. R. \& Corwin, J. T. Shape change controls supporting cell proliferation in lesioned mammalian balance epithelium. J. Neurosci. 27, 4313-4325. https://doi.org/10.1523/JNEUROSCI.5023-06.2007 (2007).

53. Tong, L., Hume, C., Palmiter, R., Rubel, E.W. Ablation of mouse cochlea hair cells by activating the human diphtheria toxin receptor (DTR) gene targeted to the Pou4f3 locus. Paper presented at the Thirty-fourth Annual Midwinter Research Meeting of the Association for Research in Otolaryngology; February; Baltimore, MD. (2011).

54. Hume, C. R., Bratt, D. L. \& Oesterle, E. C. Expression of LHX3 and SOX2 during mouse inner ear development. Gene Expr. Patterns 7, 798-807. https://doi.org/10.1016/j.modgep.2007.05.002 (2007).

55. Slattery, E. L. \& Warchol, M. E. Cisplatin ototoxicity blocks sensory regeneration in the avian inner ear. J. Neurosci. 30, 3473-3481. https://doi.org/10.1523/JNEUROSCI.4316-09.2010 (2010).

\section{Acknowledgements}

Supported by National Institutes of Health (NIH) grants R01 DC006283 (ME Warchol) and T32 DC000022 (J Piccirillo).

\section{Author contributions}

V.B. and M.W. wrote the main manuscript text, prepared figures, designed and performed experiments, M.B., H.A. and T.K. performed experiments.

\section{Competing interests}

The authors declare no competing interests.

\section{Additional information}

Correspondence and requests for materials should be addressed to V.B. or M.E.W.

Reprints and permissions information is available at www.nature.com/reprints.

Publisher's note Springer Nature remains neutral with regard to jurisdictional claims in published maps and institutional affiliations.

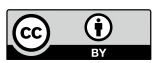

Open Access This article is licensed under a Creative Commons Attribution 4.0 International License, which permits use, sharing, adaptation, distribution and reproduction in any medium or format, as long as you give appropriate credit to the original author(s) and the source, provide a link to the Creative Commons licence, and indicate if changes were made. The images or other third party material in this article are included in the article's Creative Commons licence, unless indicated otherwise in a credit line to the material. If material is not included in the article's Creative Commons licence and your intended use is not permitted by statutory regulation or exceeds the permitted use, you will need to obtain permission directly from the copyright holder. To view a copy of this licence, visit http://creativecommons.org/licenses/by/4.0/.

(C) The Author(s) 2021, corrected publication 2021 